\title{
The Contribution of Lubricant to the Formation of Particulate Matter with Reactivity Controlled Compression Ignition in Light-Duty Diesel Engines
}

\author{
John Storey • Scott Curran • Adam Dempsey • \\ Samuel Lewis • N. Ryan Walker • Rolf Reitz • \\ Chris Wright
}

Received: 12 September 2014 / Revised: 12 November 2014 / Accepted: 1 December 2014 /Published online: 25 December 2014

(C) Springer SIP, AG 2014

\begin{abstract}
Reactivity controlled compression ignition (RCCI) has been shown in single- and multi-cylinder engine research to achieve high thermal efficiencies with ultra-low $\mathrm{NO}_{\mathrm{X}}$ and soot emissions. The nature of the particulate matter (PM) produced by RCCI operation has been shown in recent research to be different than that of conventional diesel combustion and even diesel low-temperature combustion. Previous research has shown that the PM from RCCI operation contains a large amount of organic material that is volatile and semi-volatile. However, it is unclear if the organic compounds are stemming from fuel or lubricant oil. The PM emissions from dual-fuel RCCI were investigated in this study using two engine platforms, with an emphasis on the potential contribution of lubricant. Both engine platforms used the same base General Motors (GM) 1.9-L diesel engine geometry. The first study was conducted on a single-cylinder research engine with primary reference fuels (PRFs), n-heptane, and iso-octane. The second study was conducted on a four-cylinder GM 1.9-L ZDTH engine which was modified with a port fuel injection (PFI) system while maintaining the stock direct injection fuel system. Multi-cylinder RCCI experiments were run with PFI gasoline and direct injection of 2-ethylhexyl nitrate $(\mathrm{EHN})$ mixed with gasoline at $5 \% \mathrm{EHN}$ by volume. In addition, comparison cases of conventional diesel combustion (CDC) were performed. Particulate size distributions were measured, and PM filter samples were collected for analysis of lube oil components. Triplicate PM filter samples (i.e., three
\end{abstract}

J. Storey $\cdot$ S. Curran $(\bowtie) \cdot$ A. Dempsey $\cdot$ S. Lewis

Oak Ridge National Laboratory, Oak Ridge, TN, USA

e-mail: curransj@ornl.gov

N. R. Walker $\cdot$ R. Reitz

University of Wisconsin-Madison, Madison, WI, USA

C. Wright

Wisconsin Engine Research Consultants, Madison, WI, USA individual filter samples) for both gas chromatography-mass spectroscopy (GC-MS; organic) analysis and X-ray fluorescence (XRF; metals) were obtained at each operating point and queued for analysis of both organic species and lubricant metals. The results give a clear indication that lubricants do not contribute significantly to the formation of RCCI PM.

Keywords Reactivity controlled compression ignition . Particulate matter · Low temperature combustion

\section{Introduction}

In-cylinder blending of gasoline and diesel to achieve reactivity controlled compression ignition (RCCI) has been shown to reduce $\mathrm{NO}_{\mathrm{X}}$ and particulate matter (PM) emissions while maintaining or improving brake thermal efficiency as compared to conventional diesel combustion (CDC) [1-3]. Control of the pre-mixed low reactivity fuel amount, along with control of the timing and number of injections of the direct-injected high reactivity fuel, allows for both stratification of reactivity and stratification of in-cylinder temperature and equivalence ratio. Thus, further control of combustion phasing and heat release rate is possible. The RCCI concept, as shown in Fig. 1, has an advantage over many other advanced combustion strategies [4-16] in that the fuel reactivity can be tailored to the engine speed and load, allowing stable, low-temperature combustion (LTC) operation to be extended over more of the light-duty drive cycle load range $[17,18]$.

Previous experiments have investigated the translational effects of taking CFD modeling and single-cylinder engine (SCE) experiments to multi-cylinder engines (MCE) on efficiency, emissions, and controls [17-23]. These effects include the behavior of turbomachinery and its interactions with high pressure exhaust gas recirculation (EGR), cylinder-to-cylinder 


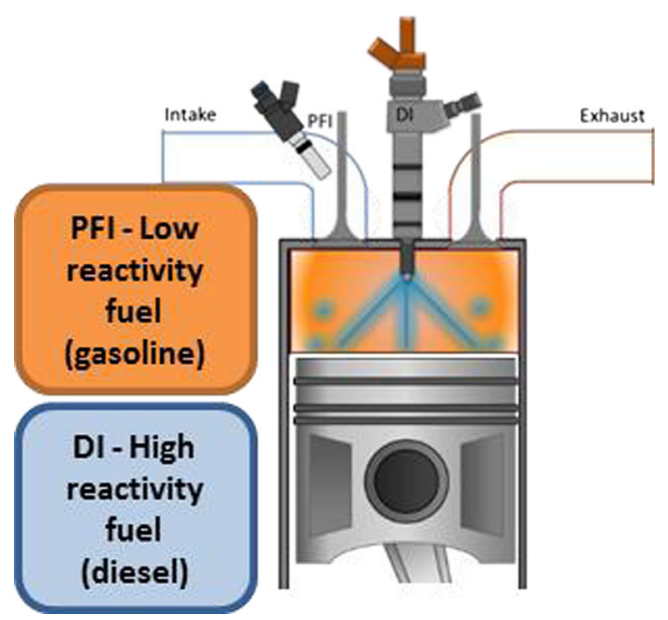

Fig. 1 RCCI injection strategy

imbalances, and swirl. Despite the translational effects, MCE RCCI has been shown to be capable of diesel-like efficiency at lower engine loads and greater than diesel efficiency at higher engine loads with an order of magnitude reduction in engine out $\mathrm{NO}_{\mathrm{X}}$ as compared to $\mathrm{CDC}$. Previous experiments have shown the benefits of increased control over the combustion process allowed by RCCI operation on extending the operating range of LTC compared to diesel premixed charge compression ignition (PCCI) on a multi-cylinder light-duty compression ignition engine [19].

While RCCI operation has been shown to produce significant reductions in NOx and soot emissions, as measured with optical reflectance methods (e.g., AVL 415S Smokemeter) or a photoacoustic soot sensor [23, 24], unburned hydrocarbons (HC), and $\mathrm{CO}$ emissions tend to increase compared to CDC. In this study, the HC emissions from RCCI operation are approximately $10 \times$ higher than CDC operation. In contrast to the low or zero soot readings, significant PM mass is observed when the exhaust is diluted for filter collection. In the USA and Europe, PM mass emissions for light-duty vehicles and heavy-duty engines are measured using a filter to collect PM mass from diluted exhaust over a drive cycle [25]. Previous research has shown that PM from LTC is different in composition and morphology than that of CDC. Early diesel LTC PM research from Sluder et al. [26] showed that the organic fraction of the PM increased dramatically and the soot portion of the PM decreased when the engine was operated in LTC mode (i.e., simultaneous low NOx and low PM compared to CDC). A follow-on study by Sluder et al. [27] showed that PM from diesel LTC operation contained a large fraction of soluble organic compounds and in some cases, significant increases in semi-volatile species were collected from the gas phase. Speciation of the PM from LTC operation showed large increases in fuel hydrocarbons and polycyclic aromatic hydrocarbons. They pointed out that this observation may result in potentially important PM measurement issues for LTC modes.
Storey et al. [28] studied the differences between CDC and diesel PCCI exhaust and found that diesel PCCI produces an increase in concentration of unregulated and toxic emissions (i.e., aldehydes and polycyclic aromatic hydrocarbons). They also observed that the PM from diesel PCCI was smaller in size compared to CDC operation. Further research on diesel PCCI from Lilik et al. [24] and Kolodziej et al. [29] found similar characteristics.

Less exhaust characterization research has been completed to date on highly premixed LTC approaches, such as HCCI and RCCI, which have been shown to have a near zero smoke number (i.e., near zero elemental carbon in the PM). Prikhodko et al. [23] compared the PM created by CDC, diesel PCCI, and RCCI on a multi-cylinder light-duty engine. Their findings were similar to Storey et al. [28], in which diesel PCCI reduces the total PM emissions, both in mass and particle concentration, as compared to CDC. In addition, the mean particle diameter is smaller, and the PM appears to be composed of less elemental carbon and more organics. For dual-fuel RCCI operation, Prikhodko et al. [23] observed that the particle concentration was reduced by 2 orders of magnitude, and the mean particle diameter is significantly smaller compared to CDC, which can be seen in Fig. 2 [23].

However, despite having far fewer particles, Prikhodko et al. [23] did observe a significant amount of mass collected on PM filters for dual-fuel RCCI operation. The filters and respective PM mass collected from CDC, diesel PCCI, and RCCI under similar load conditions are shown in Fig. 3 [23]. As can be seen, CDC operation produces roughly three times more particulate mass compared to diesel PCCI and RCCI.

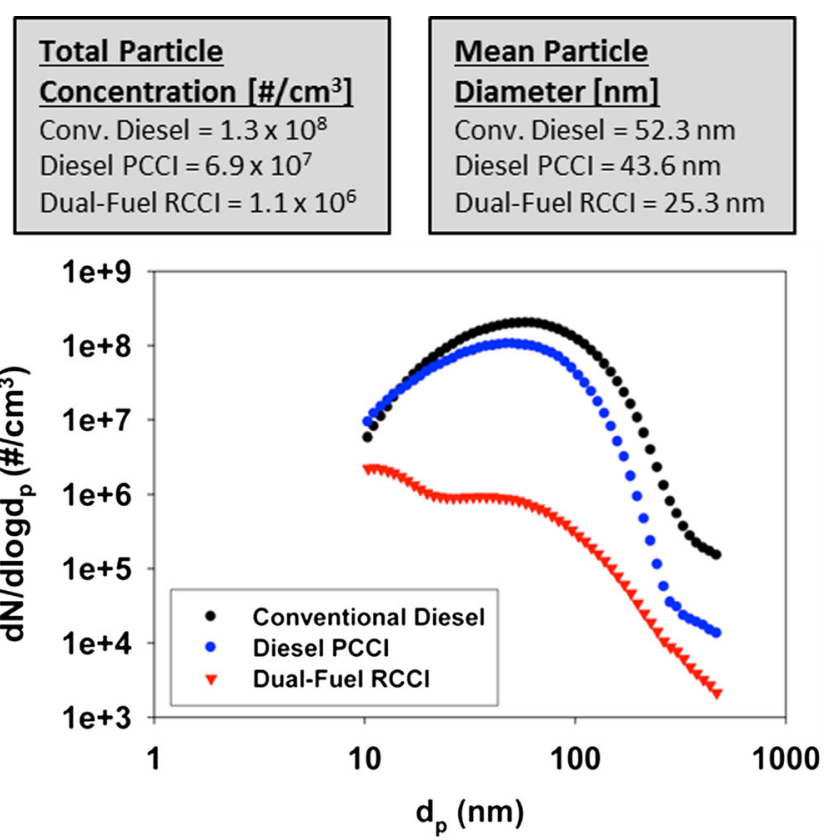

Fig. 2 Particle number concentration for CDC, diesel PCCI, and dualfuel RCCI at 4.2 bar BMEP/2300 rpm as measured by an SMPS for particles from 10 to $470 \mathrm{~nm}$ [21] 


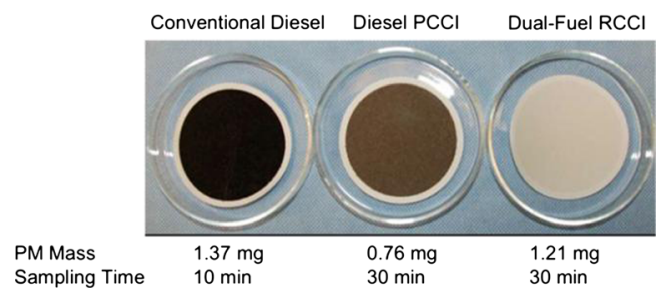

Fig. 3 Particle mass samples collected on Teflon-coated quartz-fiber filters for conventional diesel, diesel PCCI, and dual-fuel RCCI combustion at 2300 RPM, 4.2 bar BMEP [23]

Despite showing very little color, RCCI operation produces more particulate mass than diesel PCCI.

In the work of Prikhodko et al. [23], the particle concentration measured by the scanning mobility particle sizer (SMPS) was relatively low, but particulate mass collected on the filter was relatively high. This suggests that low volatility condensed organics were collected on the RCCI PM filter samples that were not measured as particles in the SMPS sample stream. However, in the particle sizing measurements, the combination of having low saturation ratios and the absence of soot in the exhaust stream prevented the formation of nucleation mode particles and the subsequent elevation of particle number concentration. Conversely, the filter matrix itself provides a suitable surface for the partitioning of the low volatility species to a particle phase, and these species are ultimately measured as particle mass. This is further supported by the lack of color from RCCI operation, suggesting that the mass collected on the filter is composed of volatile and semivolatile organics (e.g., partially oxidized hydrocarbons) as shown in Fig. 3 [23]. No definitive speciation of the HC compounds in RCCI exhaust has been completed by our laboratory, but they appear to have boiling points similar to heavy diesel fuel components or lube components, in the 150 to $200 \mathrm{C}$ range and greater.

Further research studying the PM produced by RCCI combustion has shown that the particle composition varies with engine load. Dempsey et al. [12] used multiple stages of heating and dilution to study the volatile and solid contributions to RCCI PM. The first stage of dilution was heated to $150{ }^{\circ} \mathrm{C}$, and the second stage was heated to $400{ }^{\circ} \mathrm{C}$ before being sent through another dilution tunnel to prevent condensation of the evaporated material. As shown in Fig. 4, after stage 1 dilution $\left(150^{\circ} \mathrm{C}\right)$, at low engine loads (2.6 bar BMEP), a relatively large amount of particles are measured. After a second stage of heating $\left(400{ }^{\circ} \mathrm{C}\right)$ and dilution, these particles are almost completely removed. This suggests that the engine out particles at low load are made up primarily of volatile organic material, but low volatility compounds because the particles survived heating up to $150{ }^{\circ} \mathrm{C}$. At higher engine loads ( 7.0 bar BMEP), the engine out particles from stage 1 and stage 2 are extremely low. In addition, the particles are relatively unaffected by the second stage of heating, suggesting that these particles are more solid in nature (i.e., elemental carbon). However, it is still unclear if the low volatility components of the RCCI PM stem from fuel or from lubricant oil.

Thus, despite the low or zero readings from the soot carbon measurements, there can be significant organic carbon PM mass emissions from RCCI engines. Understanding the origins and ultimately controlling the formation of the PM is critical for advancing RCCI technology. Though previous studies that have investigated RCCI PM have been able to provide insights into the make-up and nature of RCCI PM, the formation mechanism behind the measured filter mass is not well understood. The role of the two fuels and potential role of engine lubricant oil into PM formation has not been explored. In this study, experiments were performed on both singlecylinder and multi-cylinder engines of the same geometry, specifically designed to identify lubricant contributions to PM. A variety of RCCI engine conditions as well as CDC were examined, and PM was collected on filters for gravimetric, elemental/organic carbon, and X-ray fluorescence analysis. A fully synthetic lubricant was used to facilitate the identification of the lubricant components in the PM. In addition, primary reference fuel blends and gasoline mixed with a volatile additive were used as fuels for RCCI operation.
Fig. 4 Engine out particle size distributions from low- and highload RCCI operation using gasoline and diesel fuel [12]. Stage 1 sample heated to $150{ }^{\circ} \mathrm{C}$ and stage 2 sample after being heated to $400{ }^{\circ} \mathrm{C}$
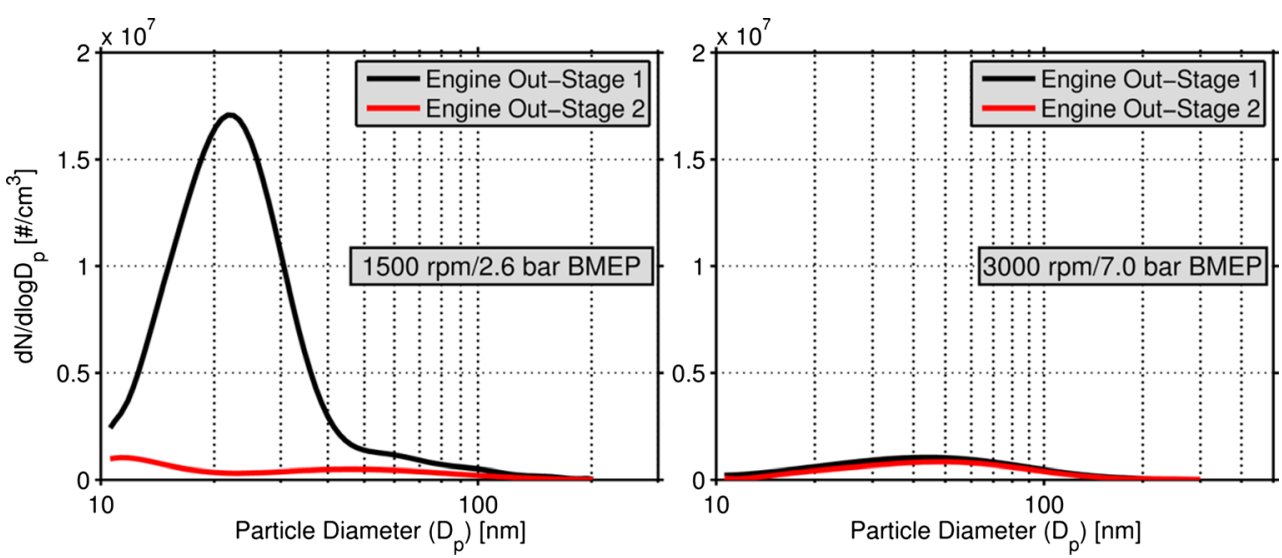


\section{Experimental}

The current study examines the potential lubricant effect on the formation of RCCI PM using two engine platforms with different fuels. The SCE experiments were performed using primary reference fuel (PRF) blends. MCE experiments were performed with conventional gasoline and gasoline mixed with a cetane improver. The SCE and MCE are based on the same GM 1.9-L engine platform. Similar PM sampling and analysis methods were used for both the SCE and MCE experiments. The following section describes the SCE and MCE experimental configurations, the fuels used, and the PM sampling techniques.

\subsection{Single-Cylinder Engine Setup}

The SCE experiments were carried out on a light-duty, fourstroke diesel engine based on the General Motors 1.9-L ZDTH platform. Table 1 shows the specifications for the engine, and Fig. 5 provides a schematic of the singlecylinder engine laboratory. A modified piston with a wide/shallow bowl was used for these experiments. The piston design is based on a heavy duty piston and minimizes the surface area of the piston to reduce heat transfer losses. The modified piston maintained the OEM compression ratio. More information regarding the piston design can be found in Hanson et al. [21]. With a bore of $82.0 \mathrm{~mm}$ and a stroke of $90.4 \mathrm{~mm}$, this engine is representative of a light-duty automotive diesel engine with four valves per cylinder driven by dual overhead cams. A stock four cylinder head is installed atop a

Table 1 Geometric specifications of a model year 2007 GM 1.9-L single-cylinder compression ignition engine

\begin{tabular}{ll}
\hline Engine geometry & \\
Geometric compression ratio (-) & 17.3 \\
Piston bowl type $(-)$ & Open \\
Displacement (L) & 0.477 \\
Stroke (mm) & 90.4 \\
Bore (mm) & 82 \\
Intake valve closing $\left({ }^{\circ}\right.$ ADTC) & -132 \\
Exhaust valve opening $\left({ }^{\circ}\right.$ ADTC) & 112 \\
Port fuel injector & \\
Included spray angle $\left({ }^{\circ}\right)$ & 20 \\
Injection pressure $($ bar $)$ & 2.5 to 3.5 \\
Rated flow (lbs/h) & 55 \\
Common rail injector & \\
Number of holes $(-)$ & 7 \\
Hole diameter $(-)$ & 0.14 \\
Included spray angle $\left({ }^{\circ}\right)$ & 148 \\
Injection pressure (bar) & 250 to 1000 \\
\hline
\end{tabular}

single-cylinder block with only the valves for cylinder \#2 activated by the cams.

\subsubsection{Single-Cylinder Engine Emission Sampling}

Engine-out emissions were measured using standard analysis techniques. A heated flame ionization detector was used to measure total unburned hydrocarbons. A heated chemiluminescence instrument was used to measure $\mathrm{NO}_{\mathrm{X}} \cdot \mathrm{CO}$ and $\mathrm{CO}_{2}$ were measured using non-dispersive infrared (NDIR) instruments. Exhaust $\mathrm{O}_{2}$ was measured using a paramagnetic detector (PMD). Both intake and exhaust $\mathrm{CO}_{2}$ were measured to provide the EGR rate. Sampled emissions were chilled before measurement by PMD and NDIR instruments to remove the water. Both intake and exhaust sample streams were conveyed from heated filters to the instruments through heated lines maintained at $190{ }^{\circ} \mathrm{C}$. An AVL 415S smoke meter was used to measure filter smoke number (FSN). Engine emissions, as well as important temperatures, pressures, flow rates, and engine speed and torque, were sampled for $180 \mathrm{~s}$ after $120 \mathrm{~s}$ of stable operation had been attained.

\subsubsection{PM Sampling for SCE}

The SCE exhaust was characterized for PM mass, chemistry, number, and size. Both raw exhaust and dilute exhaust were collected on filters. The raw exhaust filter was taken to insure that some PM was collected for the very low PM emissions in RCCI mode, and to concentrate the PM for chemical speciation. For the raw exhaust sampling, a quartz fiber filter (QFF, pre-fired Pall 2500 QAOT-UP) was mounted in an oven held at $125^{\circ} \mathrm{C}$ to avoid condensation on the filter. Raw exhaust was sampled through a heated line onto the filter, and after collection, the filter was submitted for direct thermal analysis of the PM with a gas chromatography-mass spectroscopy (GC-MS). The oven setup is shown in Fig. 6. Even though the filter was heated to prevent water condensation, it was expected to collect lubricant components and other low volatility organic carbon. In addition to raw exhaust samples, dilute exhaust samples were collected with a micro-tunnel dilution system [30]. The dilution ratio was $\sim 9$, and the dilute exhaust temperature was maintained at $40^{\circ} \mathrm{C}$. Two sampling streams with two types of filters were used: On one sample stream, a primary quartz fiber filter (QFF, pre-fired Pall 2500 QAOTUP) was collected and submitted for direct thermal analysis of the PM with GC-MS. In the second stream, a Teflon ${ }^{\circledR}$ membrane filter (TF, Pall Teflo ${ }^{\circledR}$ ) was the primary filter, followed by a secondary QFF. The TF was weighed before and after for PM mass and then sent for analysis of elements (lube metals) by X-ray fluorescence (XRF). The secondary QFF was also submitted for GC-MS analysis; the absorbed organics on the secondary QFF can be subtracted from the organics found on the primary QFF to correct for filter adsorption artifacts. The 
Fig. 5 GM 1.9-L Single-

Cylinder Engine Laboratory

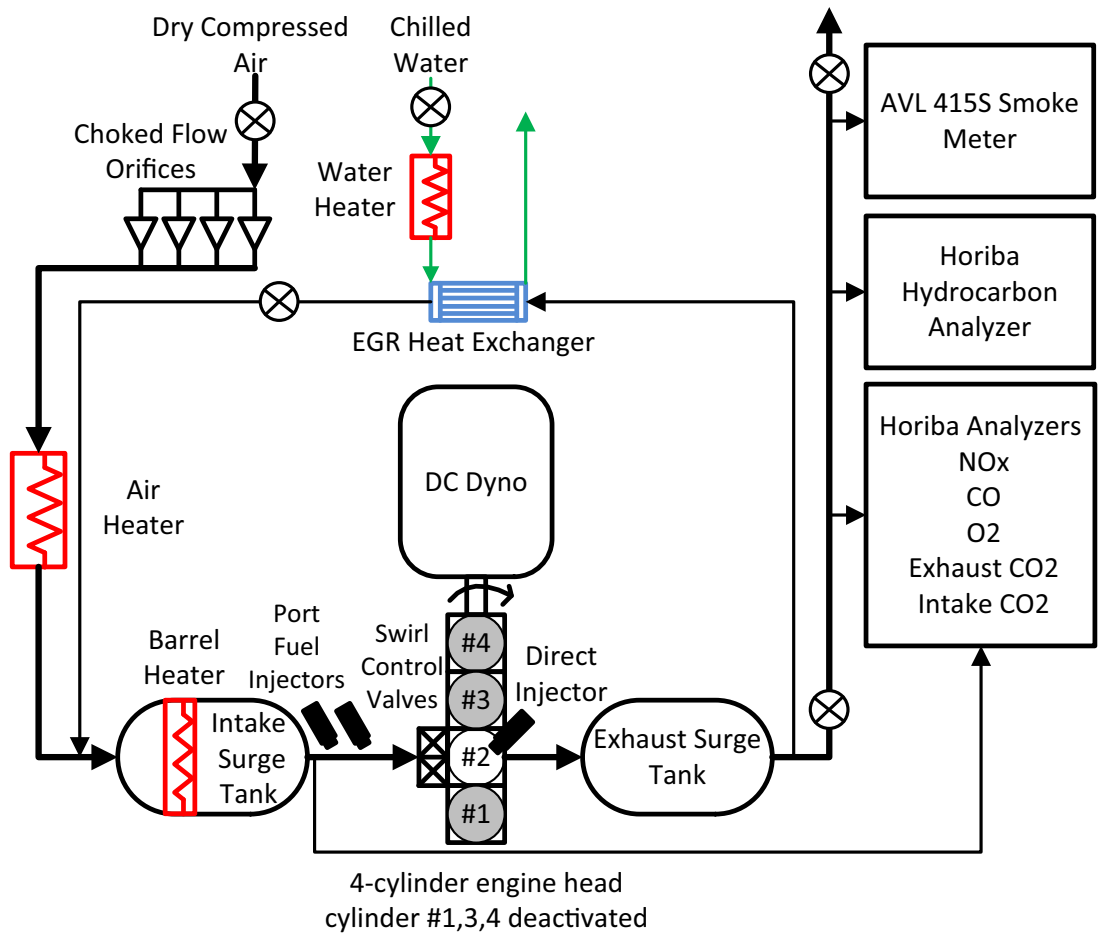

QFF has a high surface area, thus is prone to adsorption of HCs that would normally remain in the gas phase in the absence of a large surface area to adsorb to. In ambient air sampling, the tendency for QFFs to adsorb HCs has been well documented [31].

In addition to filter measurements, PM size and number measurements were made on the diluted exhaust using an Engine Exhaust Particle Sizer (EEPS, TSI, Inc.). The EEPS measures particle size distributions between 5 and $560 \mathrm{~nm}$ at $1 \mathrm{~Hz}$, and also provides a total particle number.

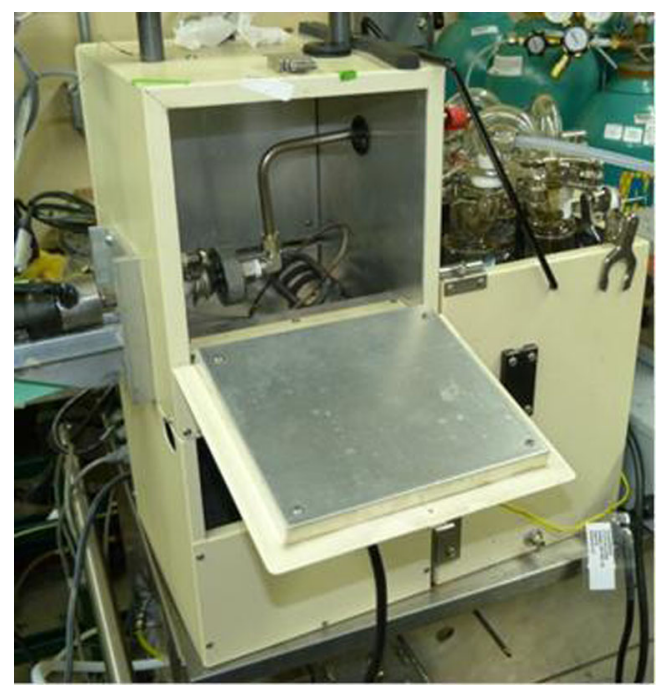

Fig. 6 Filter oven for sampling raw exhaust. The impinger glassware downstream of the filter is to condense water out prior to sample volume measurement with a dry gas meter

\subsection{Multi-Cylinder Engine Setup}

The MCE used for this study was a modified 2007 GM 1.9-L diesel engine based on the same platform as the SCE previously discussed. The original equipment manufacturer (OEM) pistons were replaced with the same pistons as the SCE, but with a reduced compression ratio. The direction injection (DI) diesel injection system and variable geometry turbocharger were left in production form. The intake manifold was modified to incorporate extended tip narrow spray-angle PFI injectors for the gasoline supply. For a more in-depth discussion, the intake manifold modifications can be found in Curran et al. [20]. Table 2 shows engine specifications for the base engine along with the injector specifications for the DI and PFI injectors. Figure 7 shows the overall fuel system layout for RCCI operation. Figure 7 also shows schematic drawing of the MCE configuration and photograph of the stock OEM piston and the modified piston bowl geometry that was used in the current study.

The stock engine control unit was replaced with a full-pass control system from National Instruments-Powertrain Controls Group (formerly Drivven, Inc.), which allowed simultaneous control of each DI injector, allowing for cylinder-to-cylinder balancing as well as all other relevant engine parameters, such as rail pressure, variable geometry turbocharger (VGT) vane position, and variable swirl actuator (VSA) position. Engine torque was measured using an AC motoring/absorbing dynamometer. The DI fuel flow rate was measured with a Max Machinery 710-213 positive displacement volumetric flow measurement system, while the PFI fuel flow rate was measured using a Micro Motion Coriolis fuel meter. The Max Machinery 
Table 2 Geometric specifications of a model year 2007 GM 1.9-L compression ignition engine

\begin{tabular}{ll} 
Four-cylinder engine geometry & \\
Geometric compression ratio $(-)$ & 15.1 \\
Piston bowl type $(-)$ & Open \\
Total displacement $(\mathrm{L})$ & 1.9 \\
Stroke $(\mathrm{mm})$ & 90.4 \\
Bore $(\mathrm{mm})$ & 82.0 \\
Intake valve closing $\left({ }^{\circ}\right.$ ADTC) & -132 \\
Exhaust valve opening $\left({ }^{\circ}\right.$ ADTC) & 116 \\
Port fuel injector & \\
Number of nozzle holes $(-)$ & 4 \\
Separation angle $\left({ }^{\circ}\right)$ & 22 \\
Cone angle $\left({ }^{\circ}\right)$ & 15 \\
Injection pressure (bar) & 3.79 \\
Common rail injector & \\
Number of nozzle holes $(-)$ & 7 \\
Hole diameter $(-)$ & 0.14 \\
Included spray angle $\left({ }^{\circ}\right)$ & 148 \\
Injection pressure (bar) & 250 to 1000 \\
\hline
\end{tabular}

meter allowed for additional cooling and vapor separation for the volatile DI fuel. The intake air flow rate was measured using a laminar flow element.

\subsubsection{MCE Emission Sampling}

Exhaust emissions were measured using standard gaseous emission analyzers. The MCE setup was similar to the SCE with the addition of intake and exhaust $\mathrm{O}_{2}$ being measured using a PMD.

\subsubsection{PM Sampling for MCE}

The MCE exhaust was also characterized for PM mass, chemistry, number, and size. Only dilute engine out exhaust samples were collected with the same micro-tunnel dilution [30] system described above. The dilution ratio was $\sim 12$, and the dilute exhaust temperature was maintained at $40{ }^{\circ} \mathrm{C}$. Two sampling streams with two types of filters were used: On one sample stream, a quartz fiber filter (QFF, pre-fired Pall 2500 QAOT-UP) was collected and submitted for thermooptical analysis of organic carbon (OC) and elemental carbon (EC). In the second stream, a Teflon ${ }^{\circledR}$ membrane filter (TF, Pall Teflo ${ }^{\circledR}$ ) was the primary filter, followed by a secondary QFF. The TF was weighed before and after for PM mass and then sent for elemental analysis by XRF (i.e., lubricant metals). The secondary QFF was also submitted for OC and EC determination; the adsorbed organics on the secondary QFF can be subtracted from the organics found on the primary QFF to correct for known filter adsorption artifacts, as discussed previously in the SCE PM Sampling section.

In addition to filter measurements, PM size and number measurements were made using a two-stage dilution system and a Scanning Mobility Particle Sizer (SMPS model 3936, TSI, Inc.). The SMPS measures particle size distributions between 10 and $500 \mathrm{~nm}$ and also provides a total particle number. The two-stage dilution system is based on an ejector pump design similar to that of the European Particle Measurement Program (PMP) [32]. This design consists of a micro-tunnel dilution system paired with an evaporator tube. In this system, raw exhaust is brought in through a critical orifice. Instrument air heated to $150{ }^{\circ} \mathrm{C}$ is drawn into the firststage diluter by an ejector pump. The first-stage diluter is maintained at $150{ }^{\circ} \mathrm{C}$.

A small portion of the first-stage flow is then sent through a $400{ }^{\circ} \mathrm{C}$ evaporator tube. The residence time in the evaporator tube is approximately $150 \mathrm{~ms}$. The sample is then brought into the second-stage dilution tunnel through a critical orifice. A second ejector pump supplied with ambient temperature instrument air draws in the second-stage dilution air. The second-stage dilution tunnel is maintained at $50{ }^{\circ} \mathrm{C}$.

The first- and second-stage total dilution ratios were approximately 12 and 80, respectively. The dilution ratio for each stage was determined from the $\mathrm{CO}_{2}$ concentration in the raw exhaust stream divided by the $\mathrm{CO}_{2}$ concentration in the dilution tunnel, as measured by an MKS FTIR. The dilution ratio was not corrected for background $\mathrm{CO}_{2}$, but the $\mathrm{CO}_{2}$ concentration in the dilution air was less than $50 \mathrm{ppm}$. The dilution air is produced using instrument grade compressed air
Fig. 7 1.9-L GM MCE

Schematic for RCCI (left) Stock GM 1.9-L piston compared to the open modified piston (right)
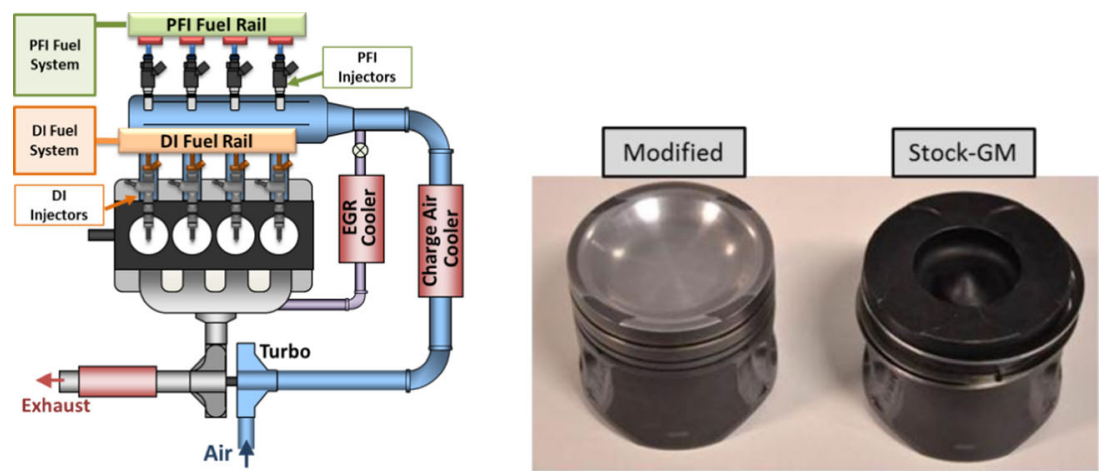
with an additional zero air conditioning system normally used for purging Fourier transform infrared (FTIR) spectrometers. The system uses pressure swing adsorption to remove $\mathrm{CO}_{2}$ and HCs.

Equipped with sampling ports after each stage, this twostage dilution system allows for both stage 1 and stage 2 SMPS sampling. A stage 1 SMPS sample consists of $150^{\circ} \mathrm{C}$ once diluted exhaust (dilution ratio of $\sim 12$ ) and thus contains solid and volatile particles. In contrast, a stage 2 sample should only consist of solid particles as the sample is taken downstream of the $400{ }^{\circ} \mathrm{C}$ evaporator tube and has been diluted again to a total dilution ratio of $\sim 80$, which will prevent reformation of nuclei and accumulation mode particles. A schematic of the system is shown in Fig. 8.

\subsection{Fuels and Lubricants}

RCCI requires the use of both a low reactivity fuel like gasoline and a more reactive fuel like diesel fuel. Considering that standard diesel fuels have some hydrocarbon species in the same range as that of lubricant oils, and this study focused on lubricant contribution to engine PM, a reactive DI fuel was needed that contained lighter hydrocarbon species.

The single-cylinder engine was operated on primary reference fuel blends. A PRF91 fuel blend (91 \% iso-octane/9\% n-heptane) was used as a surrogate for gasoline, and a PRF25 fuel blend ( $25 \%$ iso-octane $/ 75 \%$ n-heptane) was used as a surrogate for diesel fuel, the chemicals being sourced from Sigma-Aldrich.

The multi-cylinder engine used a fully formulated certification gasoline for the PFI fuel and the same gasoline with $5 \%$ EHN by volume to increase reactivity of the DI fuel, but contained lighter hydrocarbon species compared to the lubricant. In this study, the DI fuel was also doped with a lubricity additive (Infinium R655) to protect the high-pressure fuel

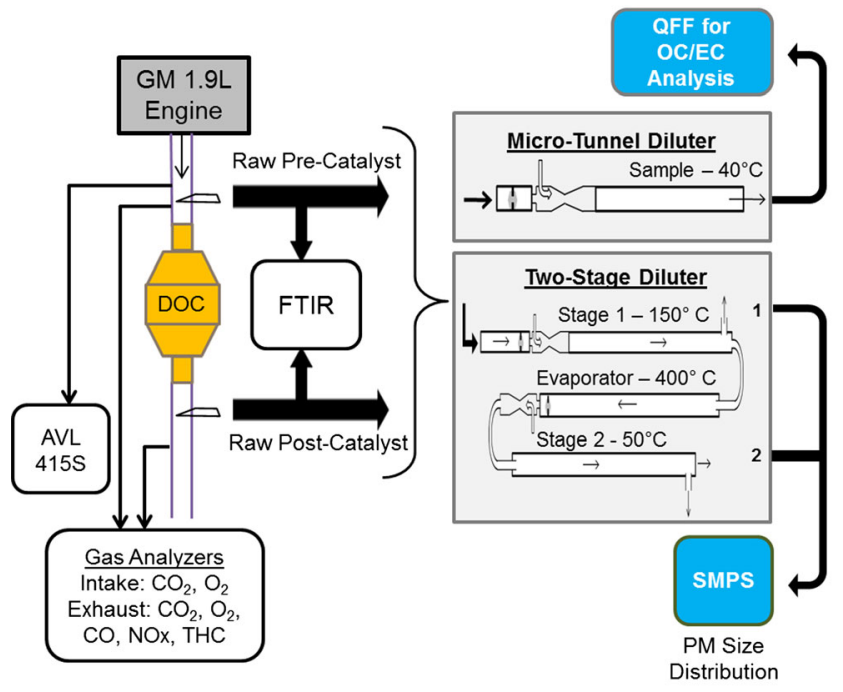

Fig. 8 1.9-L schematic of the emission equipment and the dilution systems for particulate sampling on the MCE experiments pump and the DI injectors. The specifications of the MCE fuels are shown in Table 3. Previous research by Dempsey et al. has characterized the impact of EHN on gasoline's reactivity [33]. By blending $5 \%$ EHN by volume in a gasoline with a RON of $\sim 96$, the fuel octane number was estimated to be $\sim 55$ based on HCCI combustion experiments. This is a sufficiently reactive fuel to achieve RCCI combustion with PFI of the 96 RON gasoline. The engine lubricating systems of both the SCE and the MCE were flushed well, and a fully synthetic motor oil (Mobil One ${ }^{\circledR}$ ) was used. A chromatogram of fresh Mobil One ${ }^{\circledR}$ lubricant oil will be shown for reference in a subsequent section.

\subsection{Engine Operating Points}

For the SCE and MCE engine experiments, three load points which spanned the RCCI operating range of the engine were evaluated and are shown in Table 4. The MCE operating points were chosen to yield a similar gross IMEP to the SCE experiments. For the SCE experiments, both RCCI and CDC strategies were examined for each of the three loads using the PRF fuels. The maximum load for RCCI was determined by a self-imposed peak pressure rise rate limit of $10 \mathrm{bar} /$ degree. For the MCE experiments, similar points were run with the gasoline and gasoline mixed with $5 \%$ EHN fuels. In addition, a sweep of DI start of injection (SOI) was performed at the 2300 RPM, 4.2 bar BMEP condition (point 2) for DI SOIs of $-30^{\circ}$, $-40^{\circ},-50^{\circ},-60^{\circ},-70^{\circ}$ after top dead center (aTDC). The small difference in engine rotational speed for operating point 1 and 3 was due to a dyno limitation of the SCE dynamometer.

\section{Results}

The cylinder pressure traces and heat release curves for the three operating points under both RCCI and CDC conditions for SCE experiments are shown in Fig. 9, and the engine performance and emission results are shown in Table 5.

Table 3 MCE fuel properties

\begin{tabular}{lll}
\hline Fuel usage & Certification gasoline & Cetane improver \\
\hline Chemical formula & $\mathrm{CH}_{1.88}$ & $\mathrm{C}_{8} \mathrm{H}_{17} \mathrm{NO}_{3}$ \\
Density $[\mathrm{kg} / \mathrm{m} 3]$ & 744 & 960 \\
IBP [C] & 30 & - \\
T10 [C] & 53 & - \\
T50 [C] & 107 & - \\
T90 [C] & 161 & - \\
FBP [C] & 204 & - \\
LHV [MJ/kg] & 42.88 & 27.4 \\
RON/MON & $97.2 / 88.4$ & - \\
\hline
\end{tabular}


Table 4 Speed and load points for engine experiments

\begin{tabular}{llll}
\hline Point & SCE speed/load & MCE speed/load & Description \\
\hline 1 & $1900 \mathrm{rpm} / 4.0$ bar IMEP & $2000 \mathrm{rpm} / 2.9$ bar BMEP & Oil “froth" point (low-load) \\
2 & $2300 \mathrm{rpm} / 6.0$ bar IMEP & $2300 \mathrm{rpm} / 4.2$ bar BMEP & Medium load (mid-load) \\
3 & $1900 \mathrm{rpm} / 8.5$ bar IMEP & $2000 \mathrm{rpm} / 6.5$ bar BMEP & Highest load possible SCE RCCI (high-load) \\
\hline
\end{tabular}

The cylinder pressure traces and heat release curves for the MCE experiments are shown in Fig. 10 and the SOI sweep for the mid-load RCCI point in Fig. 11. The engine performance and emission results are shown in Table 6. It should be noted that the engine out $\mathrm{NO}_{\mathrm{X}}$ emissions are elevated in the MCE experiments with DI gasoline+EHN compared to SCE experiments with PRF fuels. This expected result is due to the nitrate group on the EHN molecule [33].

\subsection{Particulate Mass Emissions}

The PM mass concentration for all of the SCE and MCE RCCI engine operating points was very low. The left hand side of Fig. 12 presents averaged results for the single-cylinder engine's three operating points with error bars showing max and min values. The lack of scatter in the RCCI PM mass data is thought to be due to the filter reaching saturated adsorption levels, which is explained below. There was more scatter in the CDC data, likely because there was significant PM formation in the combustion process, and the measurement variability is not set by filter adsorption levels. On the right hand side of Fig. 12, the PM results for three operating points and the injection sweep are compared with a CDC operating point for the MCE. Only one sample was taken at each point due to resource constraints. Of particular note is that the RCCI operating points have consistent PM mass concentrations of around 1 to $3 \mathrm{mg} / \mathrm{m}^{3}$. For both the SCE and MCE, the RCCI
PM concentrations were uniform within operating points (i.e., across the triplicate filters) and between operating points (i.e., low to high load). It is likely that the observed PM concentration represents the saturated adsorption value of the filter media, in this case the Teflon ${ }^{\circledR}$ membrane filter, which was used for PM mass determination. Because even membrane filters have some surface area, the HC emissions from RCCI operation will adsorb to the surface and reach some equilibrium at steady state. This is a small, but measurable mass, which is dependent on the volatility of the RCCI exhaust HCs. Note that the PM value is $\sim 1 \mathrm{mg} / \mathrm{m}^{3}$ for the SCE and $2 \mathrm{mg} / \mathrm{m}^{3}$ for the MCE. The SCE was using a binary reference fuel mixture which has a fixed boiling point of $\sim 100^{\circ} \mathrm{C}$, and the MCE was operating on fully formulated gasoline, with gasoline/EHN as the reactive fuel. It would be reasonable to expect, therefore, that the SCE would have lower PM values than the MCE, since the HCs are likely to be less volatile in the MCE exhaust and thus will condense on the filter more readily. In addition, the presence of aromatic HCs in the MCE fuel will likely enhance some soot formation. In the case of the CDC, the PM mass concentrations of the single-cylinder engine increase with load, as one would expect, but because soot formation is not as consistent a process as sorption equilibria, there is more scatter in the data. The CDC value for the MCE is about twice the value of the SCE, again due to the use of a fully formulated gasoline which would tend to produce more soot than the binary reference fuels.
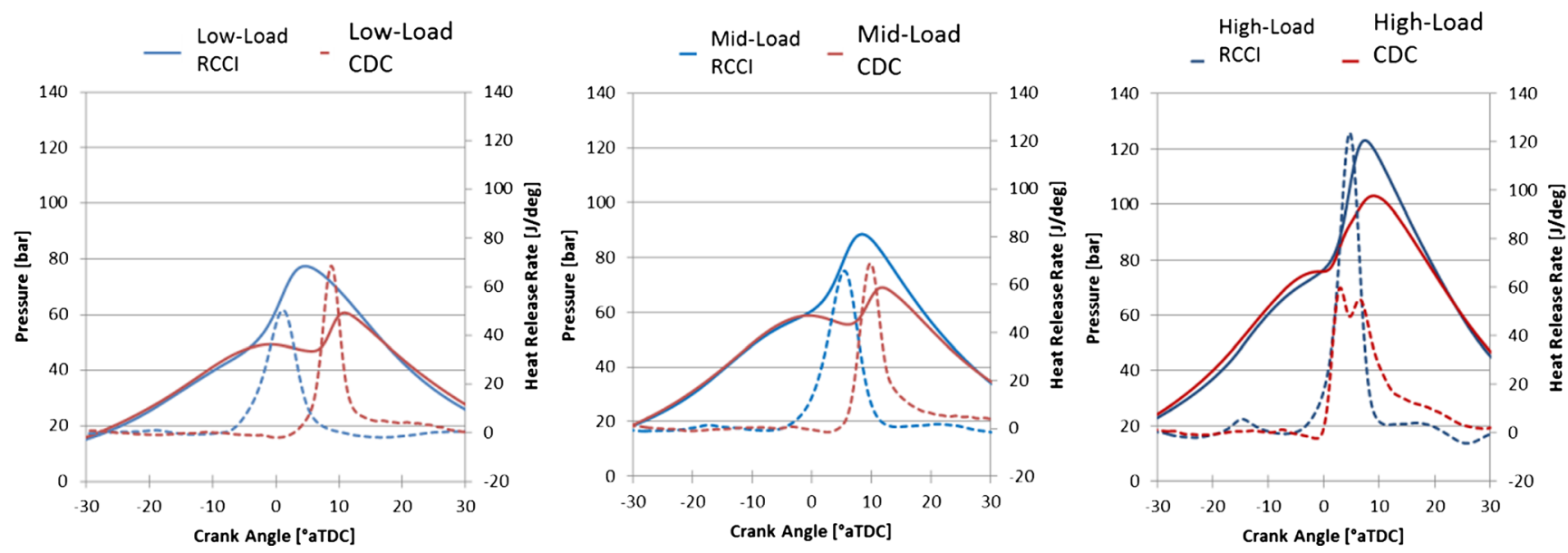

Fig. 9 SCE operating points from left to right $1900 \mathrm{rpm}, 4.0$ bar IMEP; $2300 \mathrm{rpm}, 6.0$ bar IMEP; $1900 \mathrm{rpm}, 8.5$ bar IMEP 
Table 5 Speed and load points for SCE experiments

\begin{tabular}{|c|c|c|c|c|c|c|c|}
\hline Design parameter & Unit & Low-load RCCI & Low-load CDC & Mid-load RCCI & Mid-load CDC & High-load RCCI & High-load $C D C$ \\
\hline Engine speed & {$[\mathrm{rpm}]$} & 1900 & 1900 & 2300 & 2300 & 1900 & 1900 \\
\hline Load (IMEP) & [bar] & 3.98 & 4.19 & 5.84 & 5.85 & 8.51 & 8.47 \\
\hline Port injected fuel & {$[-]$} & PRF91 & - & PRF91 & - & PRF91 & - \\
\hline Direct injected fuel & {$[-]$} & PRF25 & PRF25 & PRF25 & PRF25 & PRF25 & PRF25 \\
\hline Total fuel & {$[\mathrm{mg} / \mathrm{cyc}]$} & 10.18 & 10.07 & 13.72 & 13.44 & 18.98 & 19.82 \\
\hline Percent PFI fuel & {$[\%]$} & 68.8 & 0.0 & 90.1 & 0.0 & 88.7 & 0.0 \\
\hline DI SOIc (1st/2nd) & {$\left[{ }^{\circ} \mathrm{aTDC}\right]$} & -65 & $-17 /-7$ & $-60 /-40$ & $-18 /-7$ & $-60 /-40$ & $-18.5 /-7.5$ \\
\hline EGR/inlet $\mathrm{O}_{2}$ & {$[\%]$} & $0 / 21$ & $33.8 / 17.7$ & $0 / 21$ & $23.4 / 18.6$ & $59 / 12.1$ & $23.1 / 18.3$ \\
\hline Intake temperature & {$\left[{ }^{\circ} \mathrm{C}\right]$} & 76 & 74 & 52 & 65 & 31 & 59 \\
\hline Intake pressure & [bar abs.] & 1.01 & 1.01 & 1.25 & 1.25 & 1.65 & 1.65 \\
\hline Global $\Phi$ & {$[-]$} & 0.32 & 0.41 & 0.35 & 0.43 & 0.66 & 0.48 \\
\hline PPRR & [bar/deg] & 5.8 & 5.5 & 6.4 & 4.6 & 13.0 & 5.9 \\
\hline CA50 & {$\left[{ }^{\circ} \mathrm{aTDC}\right]$} & 0.83 & 9.50 & 5.50 & 11.50 & 4.67 & 7.75 \\
\hline Combustion eff. & {$[\%]$} & 91.3 & 98.2 & 91.9 & 98.8 & 96.3 & 99.2 \\
\hline $\mathrm{NO}_{\mathrm{x}}$ & [g/kW-hr] & 0.09 & 3.54 & 0.03 & 4.27 & 0.02 & 7.07 \\
\hline FSN & {$[-]$} & 0.02 & 0.23 & 0.02 & 0.65 & 0.03 & 0.83 \\
\hline $\mathrm{HC}$ & [g/kW-hr] & 11.86 & 1.58 & 10.31 & 1.02 & 4.55 & 0.61 \\
\hline $\mathrm{CO}$ & [g/kW-hr] & 15.21 & 5.22 & 12.30 & 3.45 & 5.08 & 2.43 \\
\hline
\end{tabular}

\subsection{Particulate Number Emissions}

Particle size distributions and number emissions were obtained on both the SCE and MCE and are shown for the mid-load point in Fig. 13. For the SCE experiments, an EEPS was used while an SMPS was used for the MCE experiments as these experiments took place in separate laboratories. Both plots in Fig. 13 have the same $y$-axis scale for comparison. Note that the overall particle concentrations were fairly similar between the two engines: $3.5 \times 10^{6}$ vs. $5 \times 10^{6}$ particles $/ \mathrm{cm}^{3}$. The lack of resolution for the SCE plot, left, was due to the use of the EEPS to take the data rather than the SMPS which was used with MCE. The large number of particles less than $15 \mathrm{~nm}$ in diameter is due to condensation of HCs in the single dilution tunnel. Experiments with a heated, two-stage evaporative dilution system confirmed that the nuclei mode disappears, which is consistent with earlier experiments in the MCE laboratory at Oak Ridge National Laboratory detailed in Prikhodko et al. [23] and Dempsey et al. [12].

\subsection{Single-Cylinder Engine-Lubricant Metals}

Elements, including those from engine wear like $\mathrm{Si}$ and $\mathrm{Fe}$, and lubricant derived like $\mathrm{Ca}, \mathrm{Zn}$, and $\mathrm{Ba}$ were analyzed with XRF. XRF has high sensitivity to elements that increases with increasing molecular weight; so, $\mathrm{Ca}, \mathrm{Zn}$, and $\mathrm{Ba}$, in particular, are good markers of lubricant in the PM. In the SCE studies, Teflon ${ }^{\circledR}$ membrane filters were collected for all of the engine points, along with a tunnel blank, which were analyzed for lube metals. Figure 14 shows the individual triplicate filter samples for each operating condition. For example, the first three sets of data are for three filters from the low-load RCCI operating condition. The exhaust concentrations of these metals were very low, below 5 ppb in most cases, as shown in Fig. 14, and highly scattered, even between identical operating points. It is worth noting that for the XRF analysis, the sensitivity for the lube metals ( $\mathrm{Ba}, \mathrm{Ca}, \mathrm{Zn}$ ) ranges from 0.4 to $1 \mathrm{ppb}$ raw exhaust concentration, and $0.3 \mathrm{ppb}$ for the wear metals ( $\mathrm{Fe}$ and $\mathrm{Si})$. When expressed as a fraction of the total PM mass, as shown in Fig. 15, it does appear that the RCCI $\mathrm{PM}$ has a higher lubricant content than CDC operation with PRF fuels and diesel fuel. This is the result of the measured PM mass being extremely low for the RCCI points. However, it is clear that the XRF analysis of the lubricant and wear metals shows that the lubricant contribution to the total PM mass for both RCCI and CDC operation is very low.

\subsection{Multi-Cylinder Engine_-Lubricant Metals}

As opposed to the simple binary PRFs used with the SCE, the MCE was operated on a fully formulated gasoline for the low reactivity fuel, and the same gasoline mixed with $5 \%$ EHN for the more reactive fuel. The results in Fig. 16 show that the metal concentrations in the exhaust are similar to those observed with the SCE, and Fig. 17 shows that the mass fractions are an order of magnitude lower than the SCE. This is due to the increased total PM mass measured on the MCE, as shown in Fig. 12. Higher levels of combustion PM during RCCI operation are expected with the MCE due to the aromatic content and 

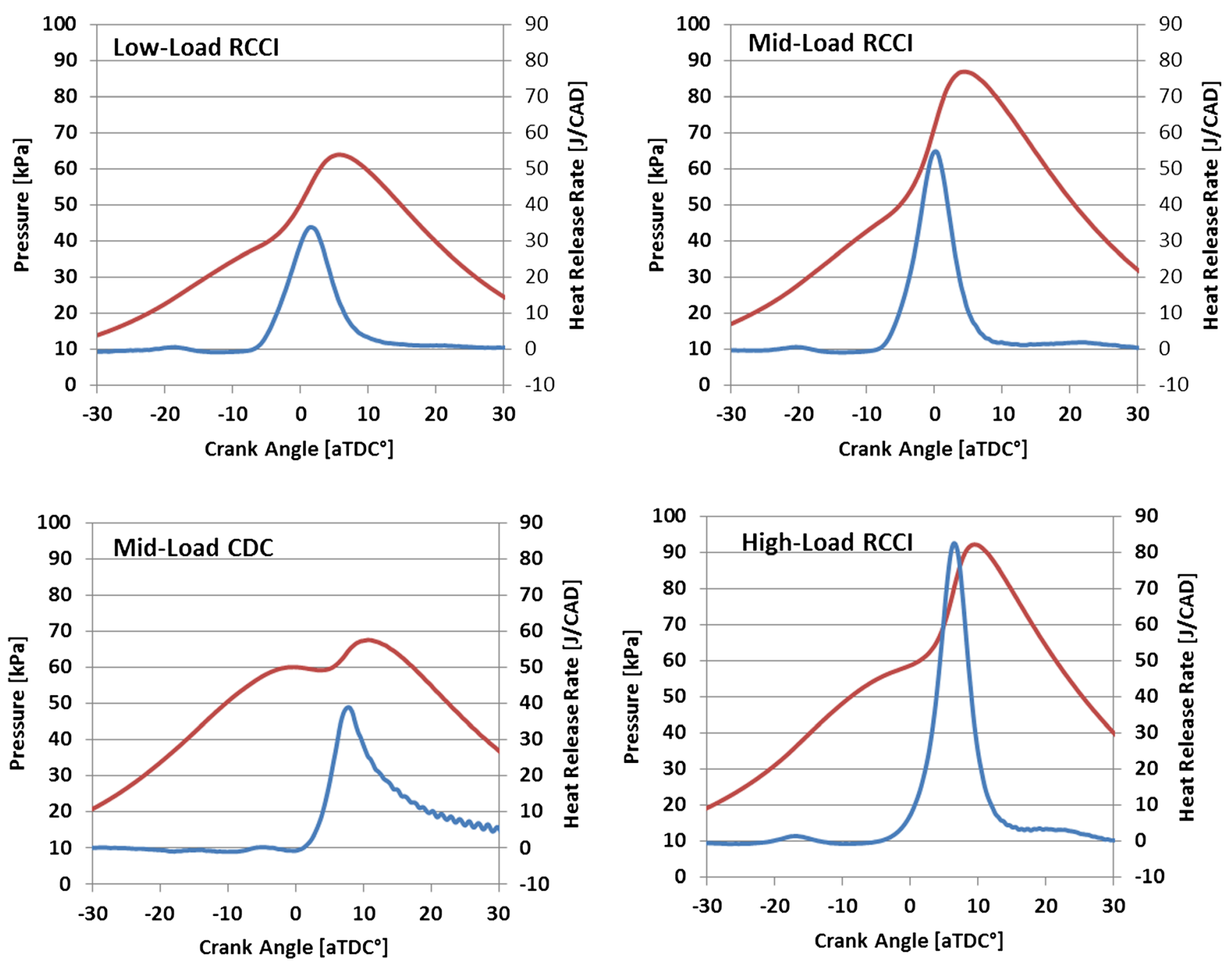

Fig. 10 MCE points from top left to bottom right: $2000 \mathrm{rpm} / 2.9 \mathrm{bar}$ BMEP, $2300 \mathrm{rpm} / 4.2 \mathrm{bar}$ BMEP, and $1900 \mathrm{rpm} / 5.9 \mathrm{bar}$ BMEP

higher boiling point of the gasoline fuel compared to the PRF fuels. The critical points of Figs. 14 and 16 are that the levels of lube metals are very low in RCCI PM (less

$$
\begin{aligned}
& \text {-SOI }=-70 \text { ATDC }-\mathrm{SOI}=-60 \text { ATDC } \quad-\mathrm{SOI}=-50 \text { ATDC } \\
& \text {-SOI }=-40 \text { ATDC }-\mathrm{SOI}=-30 \text { ATDC }
\end{aligned}
$$

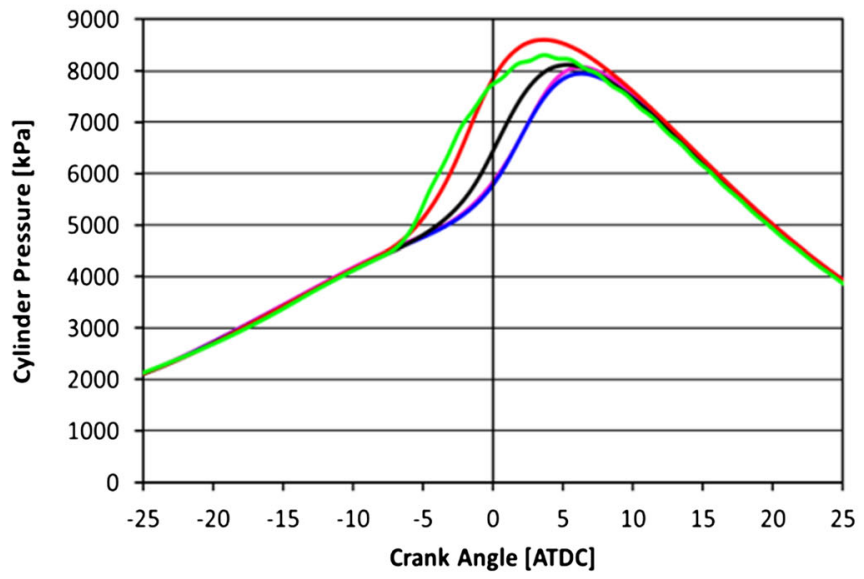

than $15 \mathrm{ppb}$ ) and there are no particular trends in any of the metal concentrations. In addition, the CDC values are as high as or higher than the results for RCCI combustion.

$$
\begin{aligned}
& -\mathrm{SOI}=-70 \text { ATDC - } \mathrm{SOI}=-60 \mathrm{ATDC}-\mathrm{SOI}=-50 \mathrm{ATDC} \\
& -\mathrm{SOI}=-40 \text { ATDC }-\mathrm{SOI}=-30 \text { ATDC }
\end{aligned}
$$

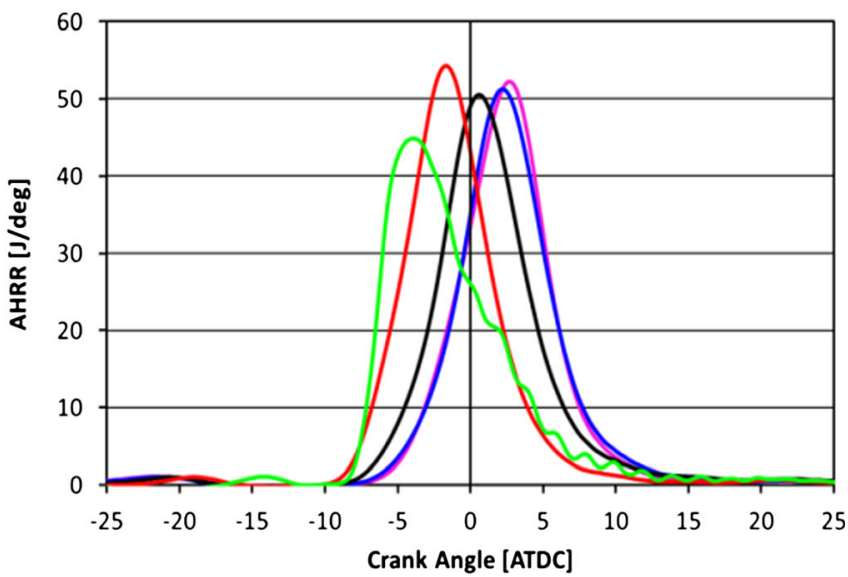

Fig. 11 MCE SOI Sweep at $2300 \mathrm{rpm} / 4.2$ bar BMEP from $-30^{\circ}$ ATDC to $-70^{\circ}$ ATDC 
Table 6 Speed and load points for MCE experiments

\begin{tabular}{|c|c|c|c|c|c|c|c|c|c|}
\hline $\begin{array}{l}\text { Design } \\
\text { parameter }\end{array}$ & Unit & $\begin{array}{l}\text { Low-load } \\
\text { RCCI }\end{array}$ & $\begin{array}{l}\text { Mid-load } \\
\text { RCCI } \\
\text { SOI -50 }\end{array}$ & $\begin{array}{l}\text { Mid-load } \\
\text { RCCI } \\
\text { SOI -60 }\end{array}$ & $\begin{array}{l}\text { Mid-load } \\
\text { RCCI } \\
\text { SOI }-40\end{array}$ & $\begin{array}{l}\text { Mid-load } \\
\text { RCCI } \\
\text { SOI -30 }\end{array}$ & $\begin{array}{l}\text { Mid-load } \\
\text { RCCI } \\
\text { SOI }-70\end{array}$ & $\begin{array}{l}\text { Mid-load } \\
\text { CDC }\end{array}$ & $\begin{array}{l}\text { High-load } \\
\text { RCCI }\end{array}$ \\
\hline Engine speed & {$[\mathrm{rpm}]$} & 2000 & 2300 & 2300 & 2300 & 2300 & 2300 & 2300 & 2000 \\
\hline Engine load & {$[\mathrm{bar}]$} & 2.8 & 4.15 & 4.14 & 4.25 & 4.08 & 4.16 & 4.3 & 5.9 \\
\hline PFI fuel & {$[-]$} & UTG96 & UTG96 & UTG96 & UTG96 & UTG96 & UTG96 & - & UTG96 \\
\hline DI fuel & {$[-]$} & $\begin{array}{l}\text { UTG96 } \\
+ \text { EHN }\end{array}$ & $\begin{array}{l}\text { UTG96 } \\
+ \text { EHN }\end{array}$ & $\begin{array}{l}\text { UTG96 } \\
+ \text { EHN }\end{array}$ & $\begin{array}{l}\text { UTG96 } \\
+ \text { EHN }\end{array}$ & $\begin{array}{l}\text { UTG96 } \\
+ \text { EHN }\end{array}$ & $\begin{array}{l}\text { UTG96 } \\
+ \text { EHN }\end{array}$ & $\begin{array}{l}\text { UTG96 } \\
+ \text { EHN }\end{array}$ & $\begin{array}{l}\text { UTG96 } \\
+ \text { EHN }\end{array}$ \\
\hline Percent PFI fuel & {$[\%]$} & 48 & 0.631 & 0.628 & 0.624 & 0.625 & 0.630 & - & 84.5 \\
\hline DI SOIc & {$\left[{ }^{\circ} \mathrm{aTDC}\right]$} & -40 & -50 & -60 & -40 & -30 & -70 & $-23 /-6$ & -60 \\
\hline DI rail press. & {$[\mathrm{bar}]$} & 500 & 500 & 500 & 500 & 500 & 500 & 650 & 500 \\
\hline Inlet $\mathrm{O}_{2}$ & {$[\%]$} & 20.95 & 20.95 & 20.95 & 20.95 & 20.94 & 20.94 & 20.95 & 20.95 \\
\hline Intake temperature & {$\left[{ }^{\circ} \mathrm{C}\right]$} & 55.0 & 55.1 & 55.3 & 55.3 & 55.3 & 55.0 & 55.0 & 26.5 \\
\hline Intake press. & [bar abs.] & 0.98 & 1.050 & 1.050 & 1.050 & 1.048 & 1.047 & 1.40 & 1.35 \\
\hline Global $\Phi$ & {$[-]$} & 0.32 & 0.35 & 0.35 & 0.35 & 0.35 & 0.35 & 0.33 & 0.40 \\
\hline PPRR & [bar/deg] & 4.7 & 5.90 & 5.46 & 7.12 & 6.90 & 5.59 & 7.0 & 9.3 \\
\hline CA50 & {$\left[{ }^{\circ} \mathrm{aTDC}\right]$} & 2.2 & 1.23 & 2.56 & -1.38 & -2.10 & 2.63 & 12.2 & 6.1 \\
\hline Comb. Eff. & {$[\%]$} & 89.1 & 93.9 & 94.2 & 94.3 & 92.2 & 94.2 & 98.6 & 93.2 \\
\hline $\mathrm{NO}_{\mathrm{x}}$ & [g/kW-hr] & 3.2 & 1.93 & 1.36 & 5.05 & 10.85 & 1.05 & 6.0 & 0.5 \\
\hline FSN & {$[-]$} & 0.01 & 0.01 & 0.00 & 0.00 & 0.02 & 0.04 & 0.96 & 0.02 \\
\hline $\mathrm{HC}$ & [g/kW-hr] & 19.2 & 11.56 & 11.45 & 10.58 & 13.63 & 12.05 & 2.5 & 12.2 \\
\hline $\mathrm{CO}$ & {$[\mathrm{g} / \mathrm{kW}-\mathrm{hr}]$} & 34.7 & 14.80 & 12.23 & 14.27 & 25.99 & 9.82 & 4.00 & 11.10 \\
\hline
\end{tabular}

\subsection{Single-Cylinder Engine- GC/MS}

Analysis of the QFFs was performed by direct thermal desorption pyrolysis gas chromatography mass spectrometry (TDP-GC-MS) [34]. A $0.5-\mathrm{cm}^{2}$ portion of the exposed filter was desorbed directly into the GC-MS and the HCs speciated. The TDP-GC-MS samples came from QFFs that were mounted in an oven at $125{ }^{\circ} \mathrm{C}$, and raw exhaust was pulled through them. The filter was heated for two reasons: to enable sampling of raw exhaust without water condensation and to bias PM collection toward less volatile components like those in lubricant oil. Long chain alkanes are major components of lubricant; so, the GC-MS analysis focused on those compounds, which typically have their most abundant mass fragment at a mass-to-charge $(\mathrm{m} / \mathrm{z})$ ratio of 57 . Figure 18 shows the ion chromatograms $(\mathrm{m} / \mathrm{z}=57)$ at the lowest load point,

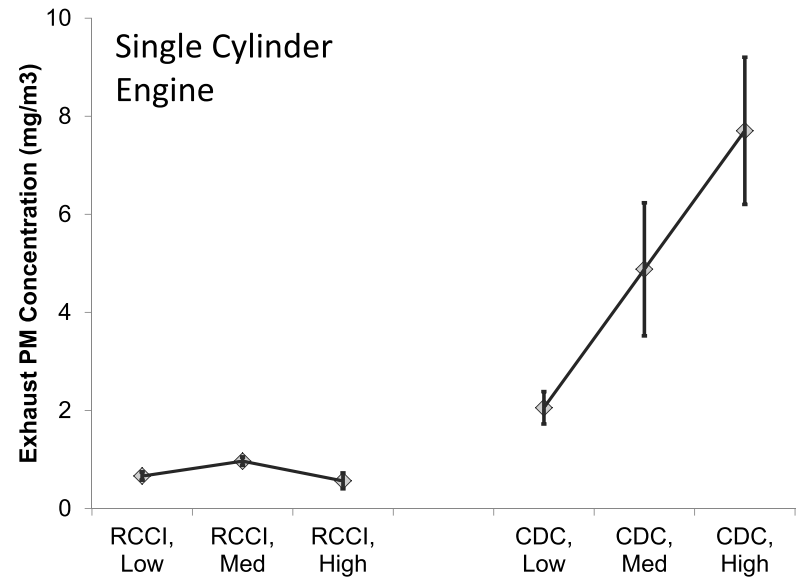

Fig. 12 PM mass results for both the SCE and MCE. For the SCE, Low, Med, and High refer to the engine operating points: $1900 \mathrm{rpm} / 4.0 \mathrm{bar}$ IMEP, $2300 \mathrm{rpm} / 6.0$ bar IMEP, and $1900 \mathrm{rpm} / 8.5$ bar, respectively. For the MCE, Low, Med, and High refer to $2000 \mathrm{rpm} / 2.9 \mathrm{bar}$ BMEP,

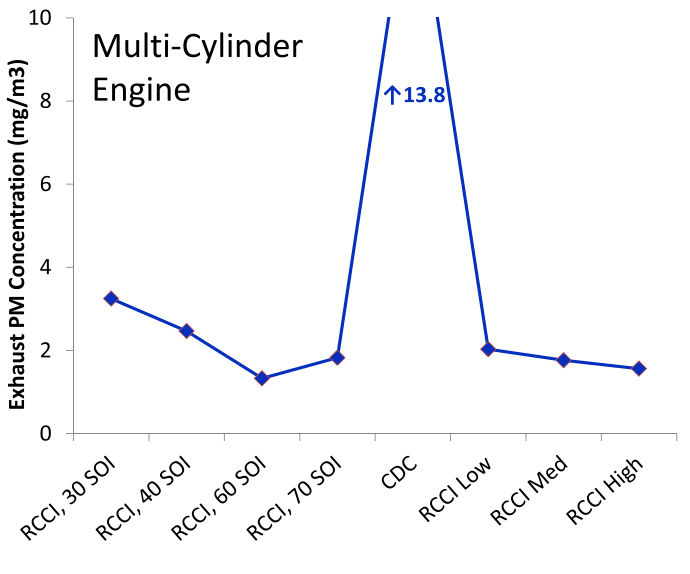

$2300 \mathrm{rpm} / 4.2 \mathrm{bar}$ BMEP, and $1900 \mathrm{rpm} / 5.9$ bar BMEP, respectively. The MCE CDC point and the injection sweeps, designated by SOI or start of injection, were done at the mid-load point 

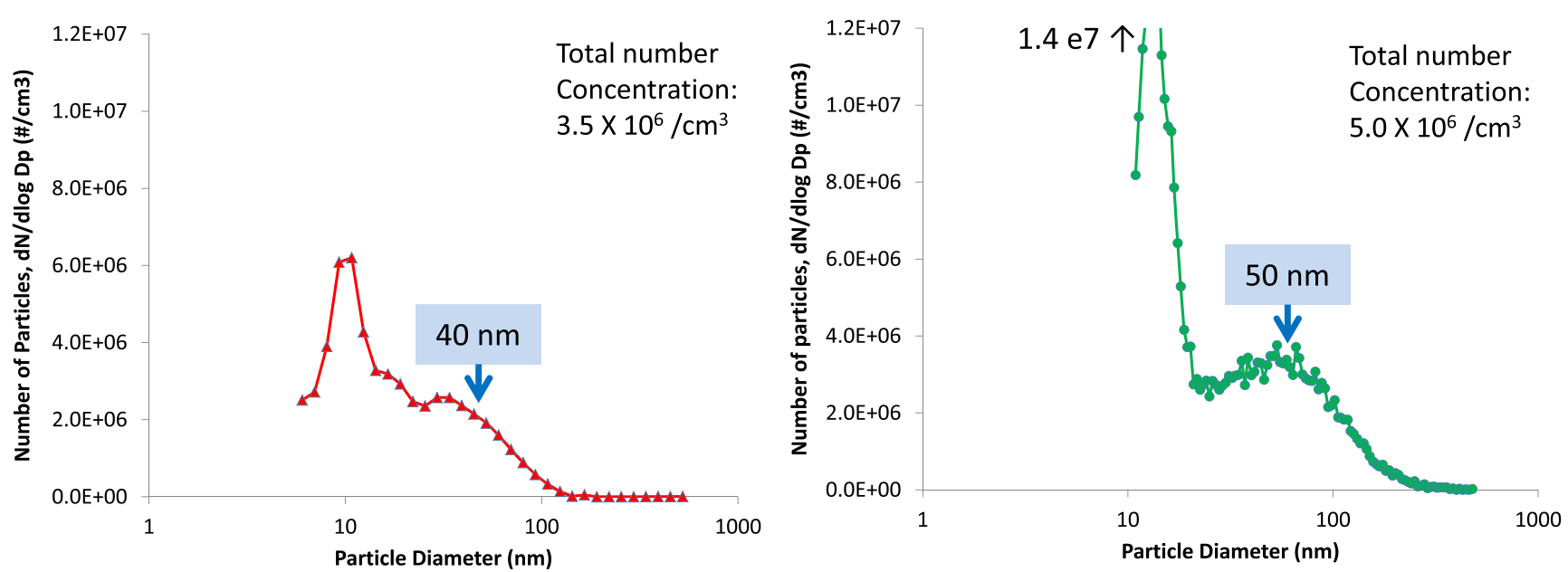

Fig. 13 Particle size distributions for the SCE at $2300 \mathrm{rpm}, 6$ bar IMEP (left side) and MCE at $2300 \mathrm{rpm}, 4.2$ bar BMEP (right side)

1900 RPM, 3.9 bar IMEP, for RCCI and CDC with the reference fuels. The response values were corrected for the differences in the volume of raw exhaust sampled. In addition, Fig. 18 includes a trace of a small amount of fresh Mobil One ${ }^{\circledR}$ lubricant analyzed with the same TDP-GC-MS apparatus. As can be seen, the lubricant's heavy alkanes are also present on the QFF sample from RCCI and CDC. Figure 19 shows the detail at the high boiling point range for the two exhaust samples (RCCI and CDC). This comparison shows that the highest boiling range compounds of the lubricant are present in RCCI exhaust, but in very small amounts, and less than the amounts collected from CDC. Both Figs. 18 and 19 illustrate that the amount of high boiling point alkanes associated with the lubricant, and collected as PM, is much lower for the RCCI point, indicating that lubricant is not a significant contributor to the PM mass in RCCI.

In order to determine a mass concentration, and thus a mass contribution of the lubricant to the overall mass, the trace shown in Fig. 18 was integrated and compared to the mass spectral response of an external standard for alkanes in this region, and normalized for volume sampled. Thus, for each of the experimental points on the single-cylinder engine, it was possible to calculate a pseudo-mass concentration of lubricant in the exhaust and a corresponding mass fraction of the PM. The mass concentrations, however, were in general below the quantitation limit ( $\sim 10 \mathrm{ppb}$ for an individual alkane) of the instrument, for RCCI PM. For CDC PM, the collected masses of individual alkanes were at or slightly above the quantitation limit of instrument. The critical point is that the exhaust concentration represented by the oil peaks is well below the quantitation limit for the RCCI points, and many of the CDC points. Thus, the oil alkanes are approximately $<1 \%$ of the total PM collected. This mass percentage is consistent with the lube metals which are of the same order. The conclusion drawn from these data are that the lubricant contribution to PM from RCCI operation is no greater than the lubricant
Fig. 14 Elemental concentration of the raw exhaust from XRF analysis for all SCE experimental points. The points are grouped into RCCI and CDC with three sample points for each load. Note that only two points were taken for the high load, CDC with PRF point. The CDC with USLD point was taken at the medium point, $2300 \mathrm{rpm} / 6.0$ bar IMEP

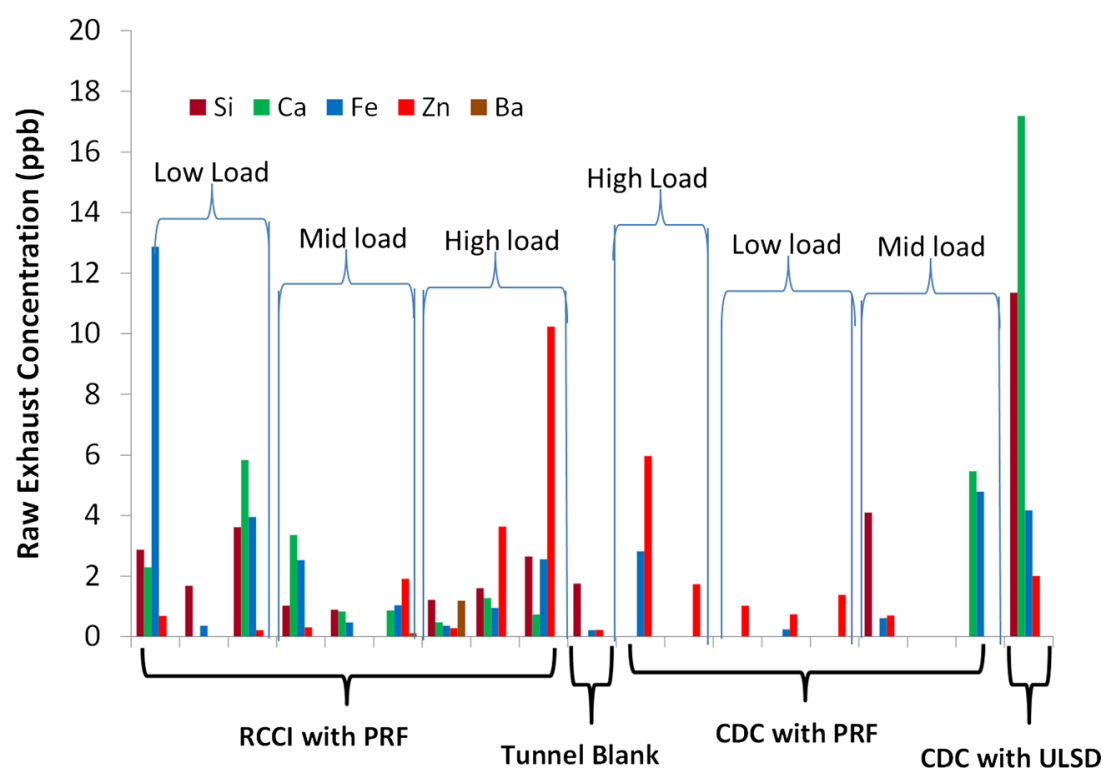


Fig. 15 XRF results of the SCE experiments are presented as a fraction of PM mass. The points are grouped the same as in Fig. 14. Note that the tunnel blank mass fraction is of the same order as the RCCI points. The CDC points have a lower mass fraction because of the higher PM mass associated with CDC

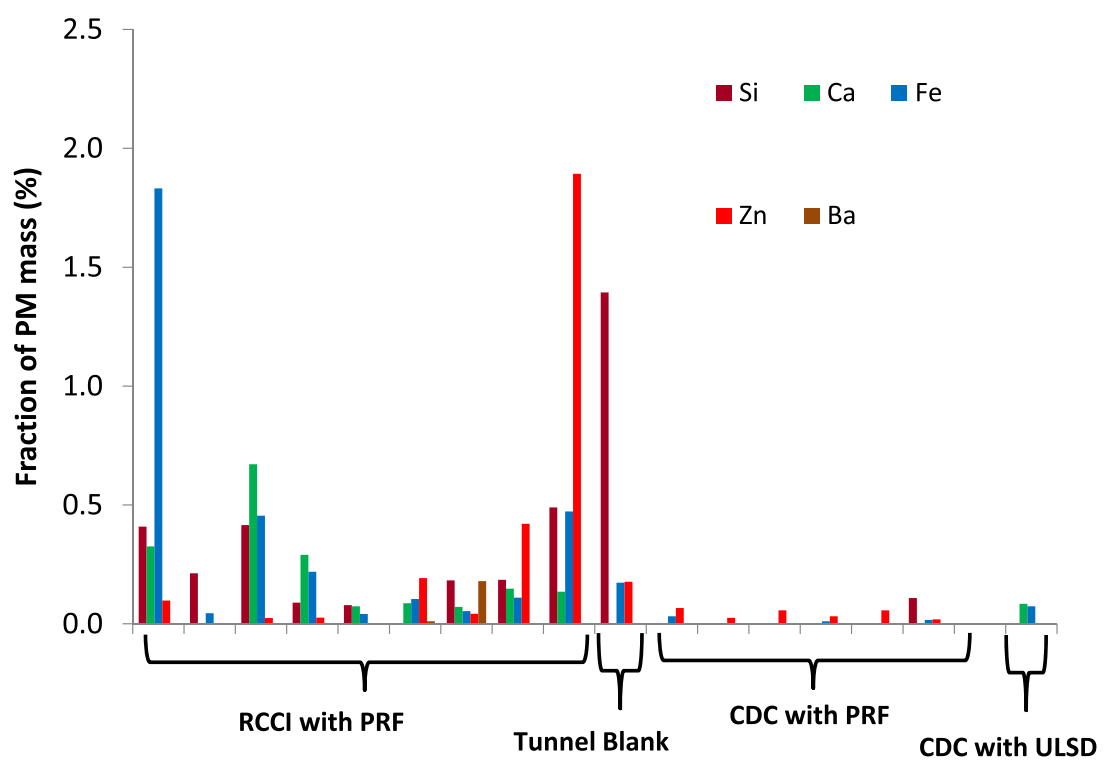

contribution to $\mathrm{PM}$ from $\mathrm{CDC}$ operation, and it is no more than $2 \%$ by mass of the total PM collected.

\subsection{Multi-Cylinder Engine OC/EC Results}

Because the raw exhaust sampling was unavailable for the MCE evaluations, no GC-MS was performed on the dilute filter samples because of the low amounts of mass collected. Instead, the QFFs were analyzed for organic carbon (OC) and elemental carbon (EC). The left hand side of Fig. 20 shows that $\mathrm{OC}$ and $\mathrm{EC}$ decrease as the start of injection (SOI) of the reactive fuel is advanced (i.e., fuel injected earlier during the compression stroke). The right hand side of Fig. 20 shows the proportion of total carbon that is OC increases as the $\mathrm{SOI}$ is advanced. For the load sweep, RCCI Low, RCCI Med, and $\mathrm{RCCI}$ High, the relative proportion of OC is similar to the SOI sweep. While the OC measurement does not distinguish between lubricant-derived HCs or combustion-derived HCs, there are two reasons why these data indicate dominance by combustion-derived HCs. The first is that the SOI sweep follows the expected trend of a higher proportion of OC with advancement of injection. The more advanced the injection, the better the pre-mixing of the fuel and air, and there is less likelihood of rich zones forming soot carbon. If lubricant was playing a big role in the OC emissions, it is unlikely that the percent OC results would show such a consistent rise. Additionally, if the lubricant was contributing significantly to the PM mass, it is thought that earlier injections (70 SOI) would have higher total PM mass than later injections (30 SOI) due to the fuel spray impinging on the liner and increasing oil consumption. This is not the case as shown in the left hand side of Fig. 20.
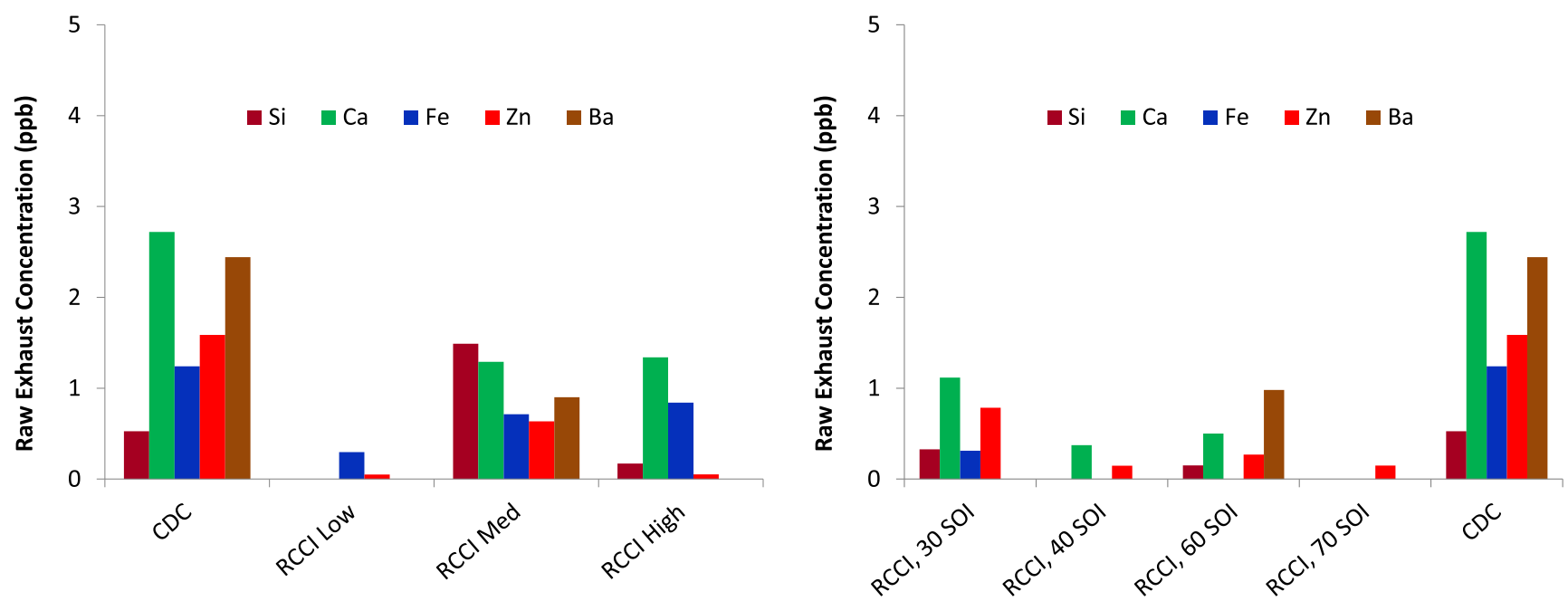

Fig. 16 XRF results for the MCE showing sub-5 ppb concentrations for lubricant and wear metals. The low, medium, and high loads were $2000 \mathrm{rpm} /$ 2.9 bar BMEP, $2300 \mathrm{rpm} / 4.2$ bar BMEP, and $1900 \mathrm{rpm} / 5.9 \mathrm{bar}$ BMEP, respectively. The SOI sweep and CDC point were performed at the mid-load point 


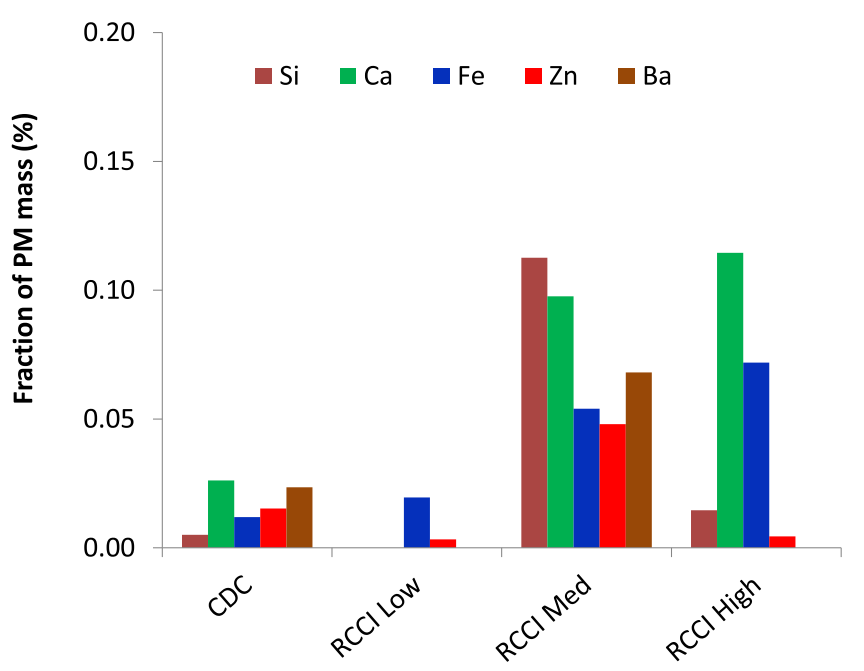

Fig. 17 XRF results for the multi-cylinder engine as PM mass fraction

\section{Summary/Conclusions}

The main goal of the current study was to investigate the potential role of engine lubricant components on the formation of measureable engine out RCCI PM. Previous studies characterizing the PM from RCCI combustion have shown that a significant contribution of the particulate mass stems from low volatility compounds (boiling point between 150 and $400 \mathrm{C}$ ), when collected on a filter. The origin of the PM collected as mass on the filter is not well understood. The role of the two fuels and potential role of engine lubricant oil into PM formation had not been explored previously. In this study,

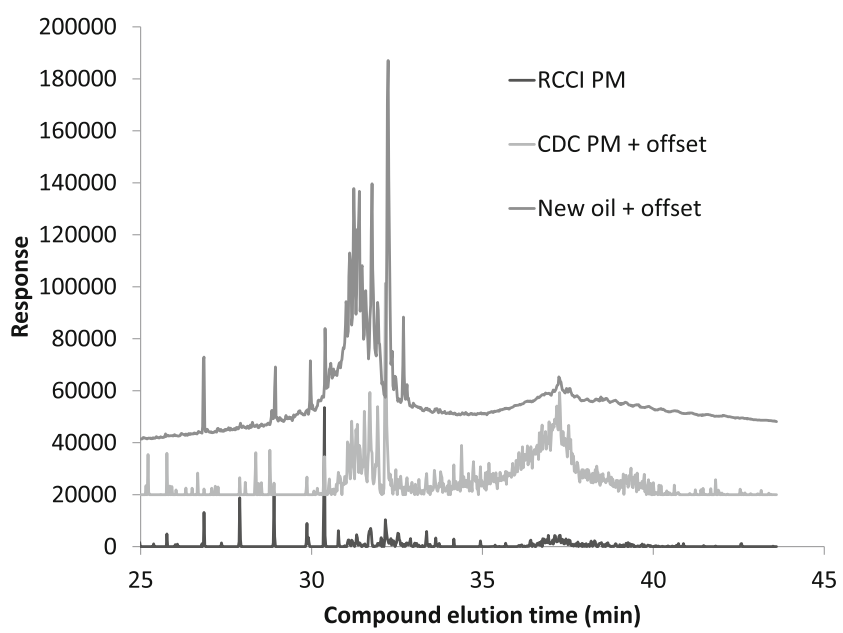

Fig. 18 Ion trace of the alkane component of the PM collected from the SCE at 1900 RPM, 3.9 bar IMEP for both the RCCI and CDC points. A fresh lubricant trace is shown as well, for comparison of the compounds present in the lube. Compound elution time refers to the time that it takes for the component to travel through the column to the detector, so the compounds represented by the peaks at $\sim 40 \mathrm{~min}$ are the highest boiling point components of the lube

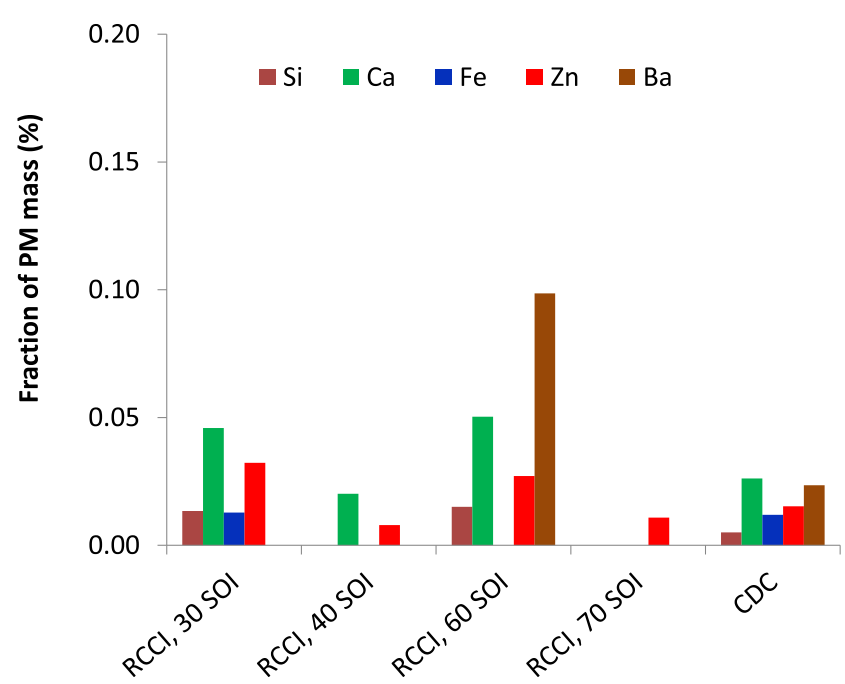

experiments, specifically designed to identify lubricant contributions to PM, were performed on both single-cylinder and multi-cylinder engines of the same geometry. A variety of RCCI engine conditions as well as CDC were examined, and PM was collected on filters for gravimetric analysis, elemental/organic carbon analysis, X-ray fluorescence analysis, and gas chromatography-mass spectroscopy. A fully synthetic lubricant was used, as well as primary reference and other high volatility fuels. Single-cylinder RCCI experiments were conducted with PFI iso-octane and DI n-heptane, while the multi-cylinder RCCI experiments were run with PFI gasoline and gasoline mixed with $5 \%$ ethyl-hexyl nitrate by volume.

Particulate characterization was performed, and PM filter samples were collected for analysis for lube oil components.

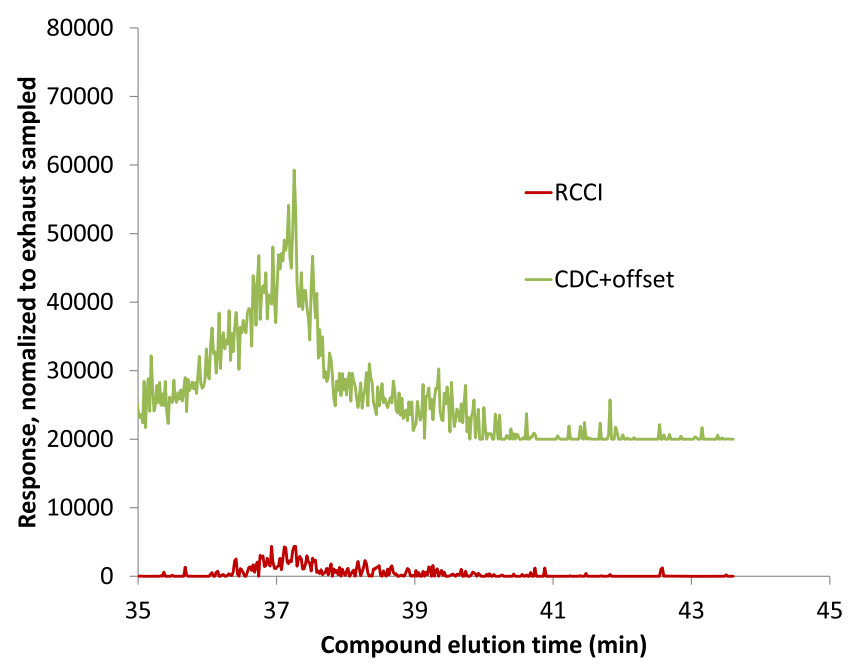

Fig. 19 Ion trace of the alkane component of the PM collected from the single-cylinder engine. This plot zooms in on the high boiling point components shown above in Fig. 18 

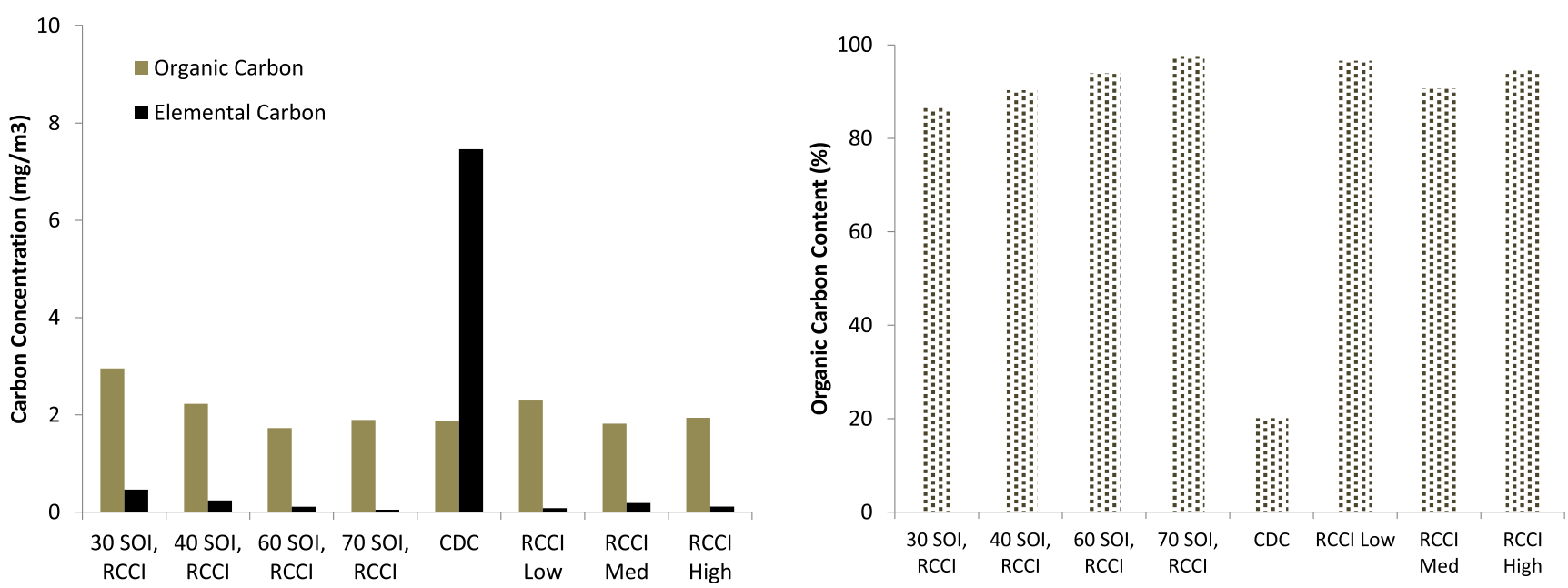

Fig. 20 Organic and elemental carbon content for the PM collected from the MCE. The injection sweep conditions were 2300 rpm, 4.2 bar BMEP, which is the same as the RCCI, medium load point. The RCCI, Low $=2000 \mathrm{rpm}, 2.9$ bar, and the RCCI, High=1900 rpm, $5.9 \mathrm{BMEP}$

Triplicate PM filter samples were taken (i.e., three individual filters for analysis). On both engines, XRF analysis measuring elemental lubricant additives ( $\mathrm{Ba}, \mathrm{Zn}$, and $\mathrm{Ca}$ ) and wear metals $(\mathrm{Fe}$ and $\mathrm{Si}$ ) showed that the contribution of lube oil to the total mass of the PM is on the order of $1 \%$, which is very low. Additionally, gas chromatography-mass spectroscopy (GC-MS) showed that the base heavy alkanes in the lubricant oil account for less than $1 \%$ of the total PM mass. Again, this was the case for both the single- and multi-cylinder engines. On the multi-cylinder, elemental/organic carbon analysis was conducted as well. It was observed that organic carbon accounts for 80 to $95 \%$ of the total PM mass, which is very different than for $\mathrm{CDC}$ operation. The measured exhaust HCs are $10 \times$ higher for RCCI combustion compared to CDC: It is reasonable to expect that some of these additional HCs are contributing to the PM mass, because it is unlikely that the additional HCs are all light gases.

The XRF and GC-MS analysis discussed previously give a clear indication that the organic carbon in the PM from RCCI operation is not stemming from the lubricant oil of the engine, but is likely due to partial oxidation of the fuel hydrocarbons due to incomplete combustion. Identification of the HC species that make up the organic carbon in RCCI PM can help to better understand the origin of the measured PM from RCCI combustion. Future experiments in the MCE laboratory at Oak Ridge National Laboratory are focusing on collecting enough of the PM for quantitative measurement of these $\mathrm{HC}$ species.

Acknowledgments Funding for this work was provided by the Department of Energy (DOE) Fuels and Lubricants Technology Program managed by Kevin Stork through a Funding Opportunity Announcement (FOA) administered by Wisconsin Engine Research Consultants, LLC.

Conflict of Interest This manuscript has been authored by a contractor for the US government under contract number DE-AC05-00OR22725. Accordingly, the US government retains a nonexclusive, royalty-free license to publish or reproduce the published form of this contribution, or allow others to do so, for the US government.

\section{References}

1. Inagaki, K., Fuyuto, T., Nishikawa, K., Nakakita, K., and Sakata, I.: "Dual-Fuel PCI Combustion Controlled by In-Cylinder Stratification of Ignitability," SAE Technical Paper 2006-01-0028, 2006, doi: 10. 4271/2006-01-0028

2. Kokjohn, S.L., Hanson, R.M., Splitter, D.A., Reitz, R.D.: Experiments and Modeling of Dual-Fuel HCCI and PCCI Combustion Using In-Cylinder Fuel Blending. SAE Int J Engines 2(2), 24-39 (2009). doi:10.4271/2009-01-2647

3. Curran, S., Hanson, R., Wagner, R.: Reactivity controlled compression ignition (RCCI) combustion on a multi-cylinder light-duty diesel engine. Int J Engine Res 13(3), 216-225 (2012)

4. Sluder, C., Wagner, R., Storey, J., et al.: Implications of Particulate and Precursor Compounds Formed During High-Efficiency Clean Combustion in a Diesel Engine. SAE 2005-01-3844, (2005)

5. Wagner, R., Green, J., Dam, T., et al.: Simultaneous Low Engine-Out NOX and Particulate Matter with Highly Diluted Diesel Combustion. SAE 2003-01-0262 (2003)

6. Sluder, C., Wagner, R., Lewis, S., et al.: Fuel Property Effects on Emissions from High Efficiency Clean Combustion in a Diesel Engine. SAE Technical Paper 2006-01-0080 (2006)

7. Sluder, C. and Wagner, R.: An Estimate of Diesel High-Efficiency Clean Combustion Impacts on FTP-75 Aftertreatment Requirements. SAE 2006-01-3311 (2006)

8. Cho, K., Han, M., Wagner, R., et al.: Mixed-Source EGR for Enabling High-Efficiency Clean Combustion Modes in a LightDuty Diesel Engine. SAE 2008-01-0645 (2008)

9. Dempsey, A., Walker, N.R., Gingrich, E., Reitz, R.D.: Comparison of Low Temperature Combustion Strategies for Advanced Compression Ignition Engines with a Focus on Controllability. Combust Sci Technol 186(2), 210-241 (2014)

10. Chadwell, C., Alger, T., Roberts, C., et al.: Boosting Simulation of High Efficiency Alternative Combustion Mode Engines. SAE 04-12$2011(2011)$

11. Manente, V., Johansson, B., and Tunestal, P.: Partially Premixed Combustion at High Load using Gasoline and Ethanol, a Comparison with Diesel. SAE 04-20-2009 (2009) 
12. Dempsey, A., Curran, S., Storey, J., Eibl, M. et al., "Particulate Matter Characterization of Reactivity Controlled Compression Ignition (RCCI) on a Light Duty Engine," SAE Technical Paper 2014-011596 (2014). doi:10.4271/2014-01-1596

13. Splitter, D., Hanson, R., Kokjohn, S., et al.: Reactivity Controlled Compression Ignition (RCCI) Heavy-Duty Engine Operation at Midand High-Loads with Conventional and Alternative Fuels. SAE 2011-01-0363 (2011)

14. Hanson, R., Kokjohn, S., Splitter, D., et al.: An Experimental Investigation of Fuel Reactivity Controlled PCCI Combustion in a Heavy-Duty Engine. SAE 2010-01-0864 (2010)

15. Kokjohn, S., Reitz, R., Splitter, D., et al.: Investigation of Fuel Reactivity Stratification for Controlling PCI Heat-Release Rates Using High-Speed Chemiluminescence Imaging and Fuel Tracer Fluorescence. SAE 2012-01-0375 (2012)

16. Kokjohn, S., Hanson, R., Splitter, D., et al.: Fuel Reactivity Controlled Compression Ignition (RCCI) Combustion in Light- and Heavy-Duty Engines. SAE 2011-01-0357 (2011)

17. Curran, S., Prikhodko, V., Cho, K., et al.: In-Cylinder Fuel Blending of Gasoline/Diesel for Improved Efficiency and Lowest Possible Emissions on a Multi-Cylinder Light-Duty Diesel Engine. SAE 2010-01-2206 (2010)

18. Curran, S., Cho, K., Briggs, T., et al.: Drive Cycle Efficiency and Emissions Estimates for Reactivity Controlled Compression Ignition in a Multi-Cylinder Light-Duty Diesel Engine. In: Proceedings of the 2011 Internal Combustion Engine Division Fall Technical Conference, ICEF2011, Morgantown WV, (2011)

19. Curran, S., Hanson, R., and Wagner, R.: Effect of E85 on RCCI Performance and Emissions on a Multi-Cylinder Light-Duty Diesel Engine. SAE 2012-01-0376 (2012)

20. Hanson, R., Curran, S., Reitz, R., et al.: Piston optimization for RCCI in Light-Duty Multi-Cylinder Engine. SAE Paper 2012-01-0380 (2012)

21. Curran, S., Szybist, J., and Wagner, R.: Reactivity Controlled Compression Ignition Performance with Renewable Fuels." ICEF2012-92192, In: Proceedings of the ASME 2012 Internal Combustion Engine Division Fall Technical Conference, ICEF2012, September 23-26, 2012, Vancouver, BC, Canada (2012)

22. Hanson, R., Curran, S., Reitz, R., et al.: Effects of Biofuel Blends on RCCI combustion in a Light-Duty, Multi-Cylinder Diesel Engine. SAE 2013-01-1653 (2013)

23. Prikhodko, V.Y., Curran, S.J., Barone, T.L., Lewis, S.A., Storey, J.M., Cho, K., Wagner, R.M., Parks, J.E.: Emission Characteristics of a Diesel Engine Operating with In-Cylinder Gasoline and Diesel Fuel Blending. SAE Int J Fuels Lubr 3(2), 946-955 (2010). doi:10.4271/ 2010-01-2266
24. Lilik, G.K., Boehman, A.L.: Advanced Diesel Combustion of a High Cetane Number Fuel with Low Hydrocarbon and Carbon Monoxide Emissions. Energy Fuel 25(4), 1444-1456 (2011). doi:10.1021/ ef101653h

25. "Emissions Standards for Light-Duty Vehicles, Light-Duty Trucks, and Medium-Duty Passenger Vehicles," Code of Federal Regulations, Part 86, Protection of the Environment. Subpart 181104, Office of the Federal Register (2001)

26. Sluder, C. S., Wagner, R. M., Lewis, S. A., and Storey, J. M. E.: "Exhaust Chemistry of Low-NOX, Low-PM Diesel Combustion," SAE Technical Paper 2004-01-0114 (2004). doi: 10.4271/2004-01-0114

27. Sluder, C. S., Wagner, R. M., Storey, J. M. E., and Lewis, S. A., "Implications of Particulate and Precursor Compounds Formed During High-Efficiency Clean Combustion in a Diesel Engine," SAE Technical Paper 2005-01-3844 (2005). doi: 10.4271/2005-013844

28. Storey, J.M.E., Lewis, S.A., Parks, J.E., Szybist, J.P., Barone, T.L., Prikhodko, V.Y.: Mobile Source Air Toxics (MSATs) from High Efficiency Clean Combustion: Catalytic Exhaust Treatment Effects. SAE Int J Engines 1, 1157-1166 (2008). doi:10.4271/2008-01-2431

29. Kolodziej, C., Wirojsakunchai, E., Foster, D. E., Schmidt, N., Kamimoto, T., Kawai, T., Akard, M., and Yoshimura, T.: "Comprehensive Characterization of Particulate Emissions from Advanced Diesel Combustion," SAE Technical Paper 2007-011945 (2007). doi: 10.4271/2007-01-1945

30. Storey, J. M. E., Domingo, N., Lewis, S.A., Irick, D.K.: “Analysis of Semivolatile Organic Compounds in Diesel Exhaust Using a Novel Sorption and Extraction Method," SAE Technical Paper Series 199901-3534 (1999)

31. Hart, K.M., Pankow, J.F.: High-volume air sampler for particle and gas sampling.2. Use of backup filters to correct for the adsorption of gas-phase polycyclic aromatic-hydrocarbons to the front filter. Environ Sci Technol 28, 655-661 (1994). doi:10.1021/es00053a019

32. Giechaskiel, B., Dilara, P., Sandbach, E., and Andersson, J.: "Particle measurement programme (PMP) light-duty inter-laboratory exercise: comparison of different particle number measurement systems," Meas Sci Technol, vol. 19, no. 9 (2008). doi: 10.1088/0957-0233/ 19/9/095401

33. Dempsey, A., Walker, N., Reitz, R.: Effect of Cetane Improvers on Gasoline, Ethanol, and Methanol Reactivity and the Implications for RCCI Combustion. SAE Int J Fuels Lubr 6(1), 170-187 (2013). doi: 10.4271/2013-01-1678

34. Storey, J., Lewis, S., Szybist, J., Thomas, J., et al.: Novel Characterization of GDI Engine Exhaust for Gasoline and MidLevel Gasoline-Alcohol Blends. SAE Int J Fuels Lubr 7(2), 571579 (2014). doi:10.4271/2014-01-1606 